\title{
The Relationship between Convective Bursts and Warm-Core Intensification in a Nonhydrostatic Simulation of Typhoon Lionrock (2016)
}

\author{
RYO OYAMA AND AKIYOSHI WADA \\ Meteorological Research Institute, Japan Meteorological Agency, Tsukuba, Japan
}

(Manuscript received 26 December 2018, in final form 14 February 2019)

\begin{abstract}
Typhoon Lionrock (2016) was unusual among tropical cyclones (TCs) in that it formed east of the monsoon gyre in the western North Pacific, and moved counterclockwise. It rapidly intensified in the monsoon gyre in an environment of weak upper-tropospheric winds and vertical wind shear. This study used a 3-km mesh nonhydrostatic model to examine the warm-core intensification of Typhoon Lionrock, which was associated with cyclone-scale vigorous convection [i.e., convective bursts (CBs)]. The simulation reproduced the multiple CBs at intervals of 1 day or shorter, which were related to the diurnal cycles and other short timescale variations in the TC convection. Each $\mathrm{CB}$ tended to precede peak temperature anomalies near the TC center by $0-12 \mathrm{~h}$, indicating that the warm-core intensification occurred due to diabatic heating released by the vigorous eyewall convection. Notably, updrafts due to convection during the intensification phase were stronger than those occurring during the mature and decay phases, and the maximum temperature anomaly of the upper-tropospheric warm core rapidly increased during eyewall formation. In addition, this study indicated that most of the asymmetric inner-core vigorous convection associated with CBs, which was induced by the vertical wind shear, contributed to the warm-core intensification. Furthermore, the budget analysis of potential temperature within the TC inner core showed that adiabatic heating due to subsidence from near the tropopause within the eye, often following CBs, was essential in developing the eye. The lag correlation suggested the lag time between the CBs and the subsidence within the eye was $3-9 \mathrm{~h}$.
\end{abstract}

\section{Introduction}

A tropical cyclone (TC) is a storm system that forms in tropical oceans where plenty of water vapor and heat fluxes are supplied. The mature hurricane and typhoon are characterized as an axisymmetric storm system with eyewall and rainbands accompanied by deep convection and strong surface winds (Houze 2010). Many studies have investigated the rapid intensification (RI) of TCs because most major hurricanes with maximum sustained winds (MSW) greater than $50 \mathrm{~m} \mathrm{~s}^{-1}$ tended to experience RI (Kaplan and DeMaria 2003). Their strong winds and heavy rainfall are often disastrous to infrastructure. Deep convection within TCs, which is enhanced by sensible heat and water vapor fluxes from the boundary layer (Braun and Tao 2000; Smith and Thomsen 2010), releases a large amount of latent heat (i.e., diabatic heat). Recurrent, vigorous convective clouds, referred to as convective bursts (CBs) (Steranka et al. 1986; Zehr 1992; Hazelton et al. 2017), often occur during the TC

\footnotetext{
Corresponding author: Ryo Oyama, royama@mri-jma.go.jp
}

intensification, and their strong updrafts and related diabatic heating are essential to the development of the TC inner core, which is generally defined as the area within 2-3 times the radius of maximum wind (RMW) (Wang 2009; Li and Wang 2012) and consists of both the eyewall and inner rainbands (e.g., Houze 2010). Observational studies showed the occurrence of CBs is often accompanied by the updraft asymmetry (Rogers et al. 2013). Rogers (2010) conducted a numerical simulation of Hurricane Dennis (2005) and indicated that CBs are precursors to RI. In addition, deep convection within the inner core transports significant absolute angular momentum and mass from the ocean surface to the upper troposphere (Sawada and Iwasaki 2007; Bryan and Rotunno 2009). These processes are essential to the development of the TC primary and secondary circulations (Shapiro and Willoughby 1982; Schubert et al. 1999; Paull et al. 2017).

In addition to their eyewall and rainbands, TCs are characterized by positive temperature anomalies and minimum central pressures relative to their surrounding atmosphere. The processes that contribute to the 
development of a warm core have been the subject of previous observational and numerical studies. Willoughby (1998) reported that both diabatic heating due to the inner-core convection and adiabatic heating within the eye intensify the warm core. Diabatic heat is released by the condensation of water vapor mainly in the mid- and lower troposphere due to deep convection, and is carried upward to develop the warm core. In this sense, deep convection is essential for TC warm-core intensification (e.g., Chen and Zhang 2013). In contrast, the atmospheric warming within the eye is caused by the compressional warming (i.e., adiabatic heating) (Zhang and Chen 2012; Elsberry et al. 2013; Kieu et al. 2016). Chen and Zhang (2013) investigated the evolution of the warm-core structure during the RI of Hurricane Wilma (2005) using a $1 \mathrm{~km}$ mesh numerical simulation and showed that the formation of the warm core in association with adiabatic heating of descending air from the lower stratosphere coincided with Wilma's RI. Ohno and Satoh (2015) investigated the contributions of the diabatic and adiabatic heating to warm-core intensification using the Nonhydrostatic Icosahedral Atmospheric Model (NICAM; Satoh et al. 2014) and showed that the contribution of diabatic heating to the intensification of the secondary circulation in TCs is large.

In recent years, numerical studies and airborne observations have indicated the roles of individual convective bursts $(\mathrm{CBs})$ in these processes of $\mathrm{TC}$ warm-core intensification via deep convection. (Fierro and Reisner 2011; Guimond et al. 2010, 2016; Hazelton et al. 2017; Rogers et al. 2013, 2015). According to observational studies using geostationary satellites, TCs have several convective time scales and periods (Muramatsu 1983; Lajoie and Butterworth 1984; Kossin 2002; Takeda and Oyama 2003). Diurnal variations are related to radiative processes and are represented by the local minimum in cloud-top temperatures associated with vigorous early morning convection and the expansion of the cirrus canopy in the afternoon (Muramatsu 1983; Lajoie and Butterworth 1984; Kossin 2002; Takeda and Oyama 2003; Dunion et al. 2014; Navarro and Hakim 2016; Navarro et al. 2017). Other variations in TC convection that occur over time scales shorter than one day, such as the semidiurnal cycle, have been recognized through analyses of vigorous convection detected by geostationary satellites (Kossin 2002; Takeda and Oyama 2003). Although these variations usually enhance convection, the influences of each deep convective cloud on warm-core intensification and related central pressure deepening have not been quantitatively evaluated. Moreover, some inconsistencies remain concerning the impact of deep convection related to the diurnal radiation cycle on TC intensification. Tang and Zhang (2016) simulated Hurricane Edouard (2014) using the Advanced Research version of the Weather Research and Forecasting (WRF) Model (ARW) and showed that the radiative cooling during the nighttime positively influenced TC intensification. Further, Melhauser and Zhang (2014) conducted ARW simulations of the pregenesis environment of Hurricane Karl (2010) and indicated that TC development can be highly sensitive to the radiative process during nighttime rather than daytime.

Here, we investigate the influence of individual deep convective clouds such as CBs, some of which occur in relation to the diurnal cycle, on the warm-core intensification of Typhoon Lionrock (2016) by using the results of a nonhydrostatic simulation. We also assess the contributions of deep convection and adiabatic heating within the eye. Further, we also aim to explore the influence of vertical wind shear on the characteristics of CBs together with $\mathrm{TC}$ warm-core intensification since there are not many previous studies focusing on it. A more in-depth understanding of these aspects of TC development will provide fundamental insights into the role of CBs in TC intensification and related structural changes.

This paper consists of five sections. Section 2 explains our numerical simulation of Typhoon Lionrock, and section 3 describes the observational data and research methodology. Section 4 presents an overview of Typhoon Lionrock and the results of our numerical simulation of warm-core intensification associated with $\mathrm{CBs}$ during each TC phase. Finally, we discuss our results and present our conclusions in section 5 .

\section{Experimental design for the simulation of Typhoon Lionrock (2016)}

To simulate Typhoon Lionrock (2016), we used an atmospheric model based on the nonhydrostatic atmosphere model (NHM; Saito 2012) coupled with a third-generation ocean and surface-wave model and a multilayer ocean model (Wada et al. 2010; Wada 2015), both developed by the Meteorological Research Institute (MRI) of the Japan Meteorological Agency (JMA). This model was applied to several simulations of Typhoons such as Typhoon Hai-Tang (2005) and Man-yi (2013) (Wada et al. 2010; Wada 2015).

The NHM includes various physical process schemes. It contains cloud physics which is expressed in an explicit three-ice bulk microphysics scheme based on the works of Ikawa and Saito (1991) and Lin et al. (1983). In addition, this model adopts an assumed resistance law used to simulate air-sea momentum, sensible and latent heat fluxes in the atmospheric surface boundary layer, exchange coefficients for air-sea momentum and enthalpy transfers over the sea based on the roughness lengths proposed by 
Taylor and Yelland (2001), a sea spray formulation from the work of Bao et al. (2000), a turbulent closure model in the atmospheric boundary layer formulated from the work of Klemp and Wilhelmson (1978) and Deardorff (1980), and an atmospheric radiation scheme based on Sugi et al. (1990). Cumulus parameterization was not used.

The computational domain of our simulation was $3000 \mathrm{~km} \times 3000 \mathrm{~km}$ centered at $33.0^{\circ} \mathrm{N}, 137.0^{\circ} \mathrm{E}$ with a horizontal grid spacing of $3 \mathrm{~km}$. The integration time was $210 \mathrm{~h}$ with time steps of $3 \mathrm{~s}$ in the NHM, $18 \mathrm{~s}$ in the ocean model, and $10 \mathrm{~min}$ in the ocean wave model. The simulation ran from 0000 UTC 23 August to 1800 UTC 30 August 2016. The NHM had 55 vertical layers with variable intervals from $40 \mathrm{~m}$ near the surface to $1013 \mathrm{~m}$ for the uppermost layer; the top height was approximately $26 \mathrm{~km}$. We used the JMA's global objective analysis data for the initial and boundary atmospheric conditions (horizontal grid spacing of about $20 \mathrm{~km}$ ) and daily oceanic reanalysis data with a horizontal grid spacing of $0.5^{\circ}$ calculated by the MRI's multivariate ocean variational estimation (MOVE) system (Usui et al. 2006). The lateral boundary atmospheric condition of the computational domain, which is given from the global objective analysis data, is updated every $6 \mathrm{~h}$. The interval of model output was $1 \mathrm{~h}$ from the initial time to $108 \mathrm{~h}$ and was $20 \mathrm{~min}$ after $108 \mathrm{~h}$.

\section{Data and methods}

\section{a. JMA and JTWC best track data}

For reference data of Typhoon Lionrock's position and intensity, we used the positions and the $10 \mathrm{~min}$ average maximum sustained wind (MSW) and the minimum sea level pressure (MSLP; also referred to as the central pressure) from the best track data archived by the Regional Specialized Meteorological Center (RSMC) Tokyo-Typhoon Center of the JMA. The radius of $30 \mathrm{kt}\left(15.4 \mathrm{~m} \mathrm{~s}^{-1}\right)$ winds (hereafter R30), used to represent TC size, was reported by the RSMC based on satellite observations, including sea surface winds by the ASCAT scatterometer of Meteorological Operational satellites (MetOp) series polar-orbiting satellites (Gelsthorpe et al. 2000) and the size of the central dense overcast in infrared brightness temperature (TB) images by geostationary satellites (Kishimoto et al. 2013).

To verify the RMW of the simulated Typhoon Lionrock, we used the RMW of the Joint Typhoon Warning Center (JTWC) best track data because the RSMC Tokyo-Typhoon Center does not provide RMW.

\section{b. Research methodology}

This study investigated the updrafts related to convection and the warm-core intensity within a radius of RMW multiplied by 3 from the TC center (hereafter referred to as 3RMW) in the simulation of Typhoon Lionrock. The radius of $3 \mathrm{RMW}$ was determined to be sufficient to cover the TC inner core (Croxford and Barnes 2002) and is similar to that used to examine CBs by Steranka et al. (1986) and Oyama (2017). To investigate more vigorous convective updrafts within the TC inner core, this study defined a convective burst (referred to as "CB") grid where the vertical velocities for all layers in the troposphere are positive. The CB grid is defined as the grid where the rainfall intensity is greater than $0 \mathrm{~mm} \mathrm{~h}^{-1}$, the vertically averaged vertical velocity in the layer of $300-700 \mathrm{hPa}$ is greater than $5 \mathrm{~m} \mathrm{~s}^{-1}$, and that in the layer of $700-850 \mathrm{hPa}$ is greater than $0.5 \mathrm{~m} \mathrm{~s}^{-1}$ by referring to Rogers (2010). We used the horizontally averaged updrafts at each height for $\mathrm{CB}$ grids within a radius of $3 \mathrm{RMW}$ for investigating the vertical profile of the updraft for CBs. The warm core was detected using the temperature anomaly from the average temperature within the annuli between 550 and $600 \mathrm{~km}$ from the TC center (Oyama 2014).

We further investigated the vertical wind shear (VWS) near Typhoon Lionrock because it is known to negatively influence the TC intensity and distort the TC structure (Paterson et al. 2005; Ueno 2007). VWS is defined as the wind difference between 200 and $850 \mathrm{hPa}$ averaged within the radius of $600 \mathrm{~km}$ from the TC center (TC inner core is included for this averaging). Regarding the impact of the radius on VWS over Typhoon Lionrock, we tried using several radii such as 500, 600, and $700 \mathrm{~km}$ for computing the VWS and showed that the magnitude of VWS was not significantly influenced by the selection of radius. Also, we investigated the impact of including TC inner core (radius $<150 \mathrm{~km}$ ) on the VWS computation and found that it was small.

\section{Results}

\section{a. Overview of Typhoon Lionrock (2016)}

This study simulated Typhoon Lionrock (2016) using the high-resolution nonhydrostatic atmosphere model coupled with ocean and ocean wave models (section 2). Typhoon Lionrock formed as a tropical depression (TD) in the eastern part of the monsoon gyre (Lander 1994; Wu et al. 2013) with a synoptic cyclonic circulation in the western North Pacific, in which the relatively weak upper tropospheric winds and VWS existed, at 0000 UTC 17 August 2016. The TD became a tropical storm stage with MSW greater than $34 \mathrm{kt}\left(17.5 \mathrm{~m} \mathrm{~s}^{-1}\right)$ at $1200 \mathrm{UTC}$ 21 August 2016. It then moved counterclockwise during rapid intensification with multiple $\mathrm{CBs}$ in the monsoon gyre. The weak winds and VWS around Typhoon Lionrock during the intensification phase were favorable for its intensification and did not distort its structure 


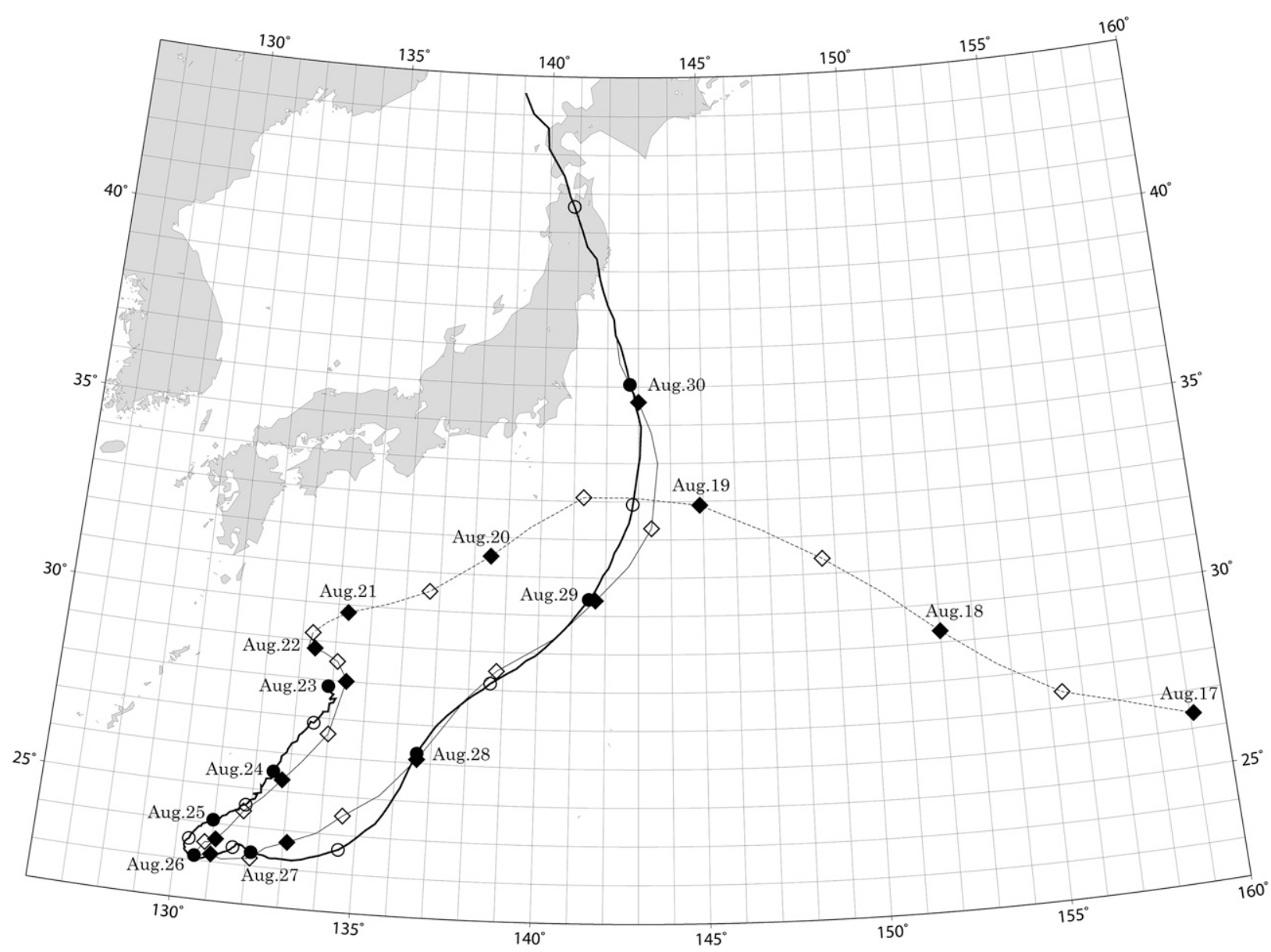

FIG. 1. The tracks of Typhoon Lionrock (2016) from the JMA best track data (diamonds with thin line) compared to that in the simulation (circles with bold line). Closed and open symbols denote 0000 and 1200 UTC, respectively. Dotted and solid lines in this figure denote the tropical depression period (TD; 0000 UTC 17 Aug-1100 UTC 21 Aug 2016) and typhoon period (1200 UTC 21 Aug-1200 UTC 30 Aug 2016), respectively.

(Gallina and Velden 2002; Wong and Chan 2004; Paterson et al. 2005). This TC turned toward the east near the Minamidaito-Jima (Fig. 1) as a result of the approach of a midlatitude southwesterly jet. The central pressure and MSW during the mature phase reached $940 \mathrm{hPa}$ and $46 \mathrm{~m} \mathrm{~s}^{-1}$, respectively.

\section{b. Simulated track and intensity of Typhoon Lionrock and the environments}

Typhoon Lionrock was well reproduced in the numerical simulation; its simulated positions, specified as the minimum surface pressure positions, were similar to the JMA's best track data (Fig. 1). MSW and MSLP in the simulation were also similar to those in the best track data (Fig. 2a). The lifetime minimum MSLP occurred approximately $60 \mathrm{~h}$ earlier in the simulation (1800 UTC 25 August) than in the best track data (0600 UTC 28 August).
As shown in Fig. 2a, we defined the intensification, mature, and decay phases of the simulated Typhoon Lionrock on the basis of the simulated MSLP as the periods between 0000 UTC 23 August and 1800 UTC 25 August, between 1800 UTC 25 August and 0000 UTC 29 August, and between 0000 UTC 29 August and 1800 UTC 30 August, respectively.

Figure $2 \mathrm{~b}$ shows the RMW of the simulated Typhoon Lionrock which was derived from the $10 \mathrm{~m}$ height winds of the simulation, and sea surface temperature (SST) averaged within a radius of $150 \mathrm{~km}$ from the center of the simulated TC. The RMW gradually decreased from about 40 to $20 \mathrm{~km}$ during the intensification phase, then gradually increased from the mature phase to the decay phase. It should be noted that the RMW of JTWC best track data is similar to that for the simulation (Fig. 2b), suggesting that the simulation reproduced the inner-core structure of Typhoon Lionrock well. SST was 

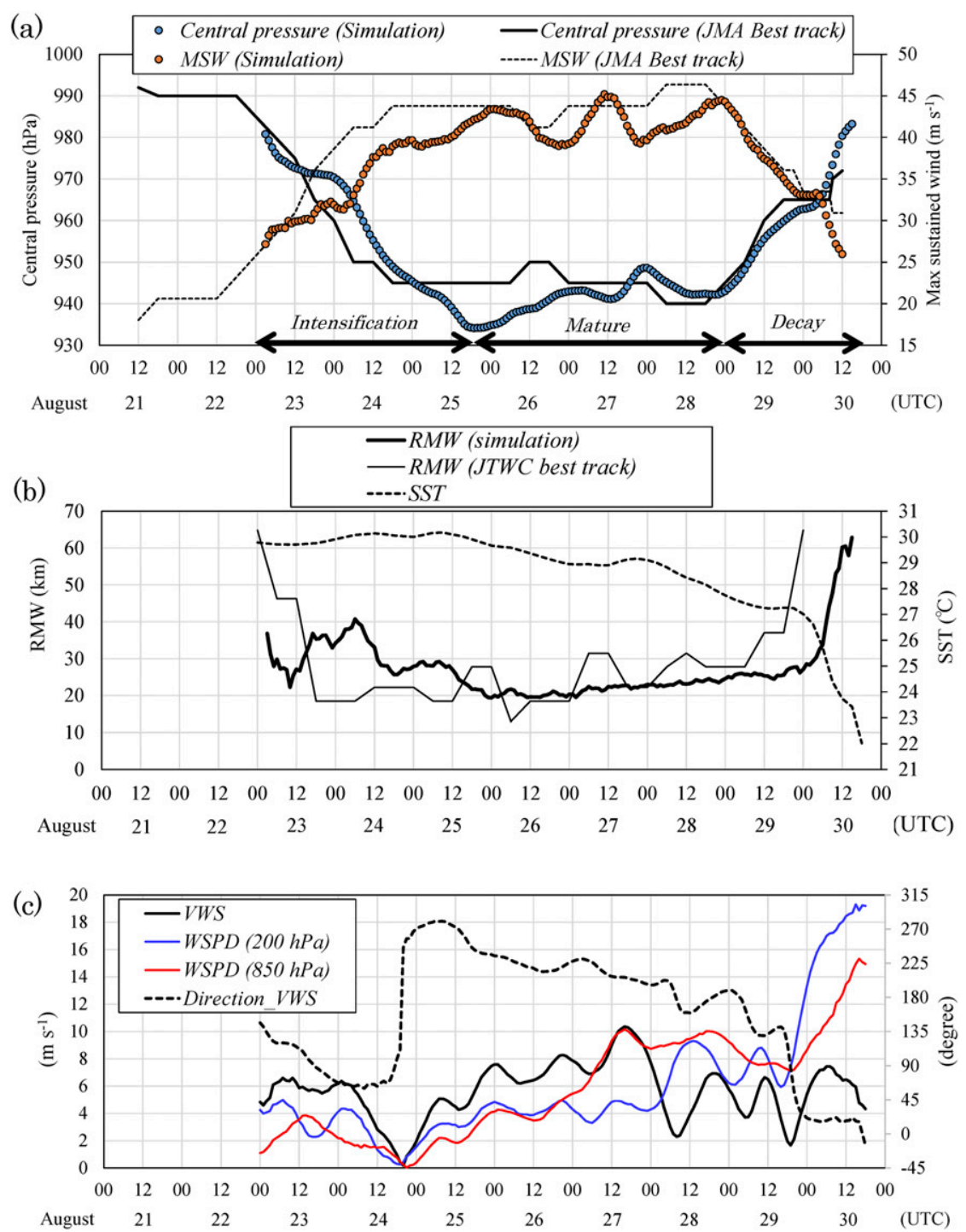

FIG. 2. (a) Time series of 6-h running-mean central pressures and maximum sustained winds (MSW) in the simulation and the JMA best track data of Typhoon Lionrock (2016). The intensification, mature, and decay phases are defined on the basis of the central pressures in the simulation; (b) the radius of maximum wind at 10-m height (RMW) for the simulation (bold solid line) and JTWC best track data (thin solid line), and sea surface temperature (SST; broken line) within the radius of $150 \mathrm{~km}$ from the TC center in the simulation; and (c) mean vertical wind shear (VWS; black line) and direction (broken line) between 200 and $850 \mathrm{hPa}$ levels and mean wind speeds (WSPD) within a $600 \mathrm{~km}$ radius from the TC center at 200 (blue line) and $850 \mathrm{hPa}$ (red line) levels in the simulation. Directions of $0^{\circ}, 90^{\circ}, 180^{\circ}$, and $270^{\circ}$ denote north, east, south, and west, respectively.

greater than $29.5^{\circ} \mathrm{C}$ during the intensification phase, which indicates that Typhoon Lionrock existed over the ocean which is favorable for TC intensification.

The VWS within a radius of $600 \mathrm{~km}$ from the TC center was relatively small, less than $10 \mathrm{~m} \mathrm{~s}^{-1}$ during the intensification phase (Fig. 2c), though it was slightly higher than the VWS which was retrieved from the Advanced Microwave Sounding Unit (AMSU) observations by the Cooperative Institute for Research in the Atmosphere (CIRA) (Zehr et al. 2008) (http://rammb.cira. colostate.edu/products/tc_realtime/storm.asp?storm_ identifier $=$ WP122016). The relatively small VWS implies that the environmental winds around the TC may not have negatively influenced its intensity and structure (Gallina and Velden 2002; Wong and Chan 2004; Paterson et al. 2005). The direction of VWS was 

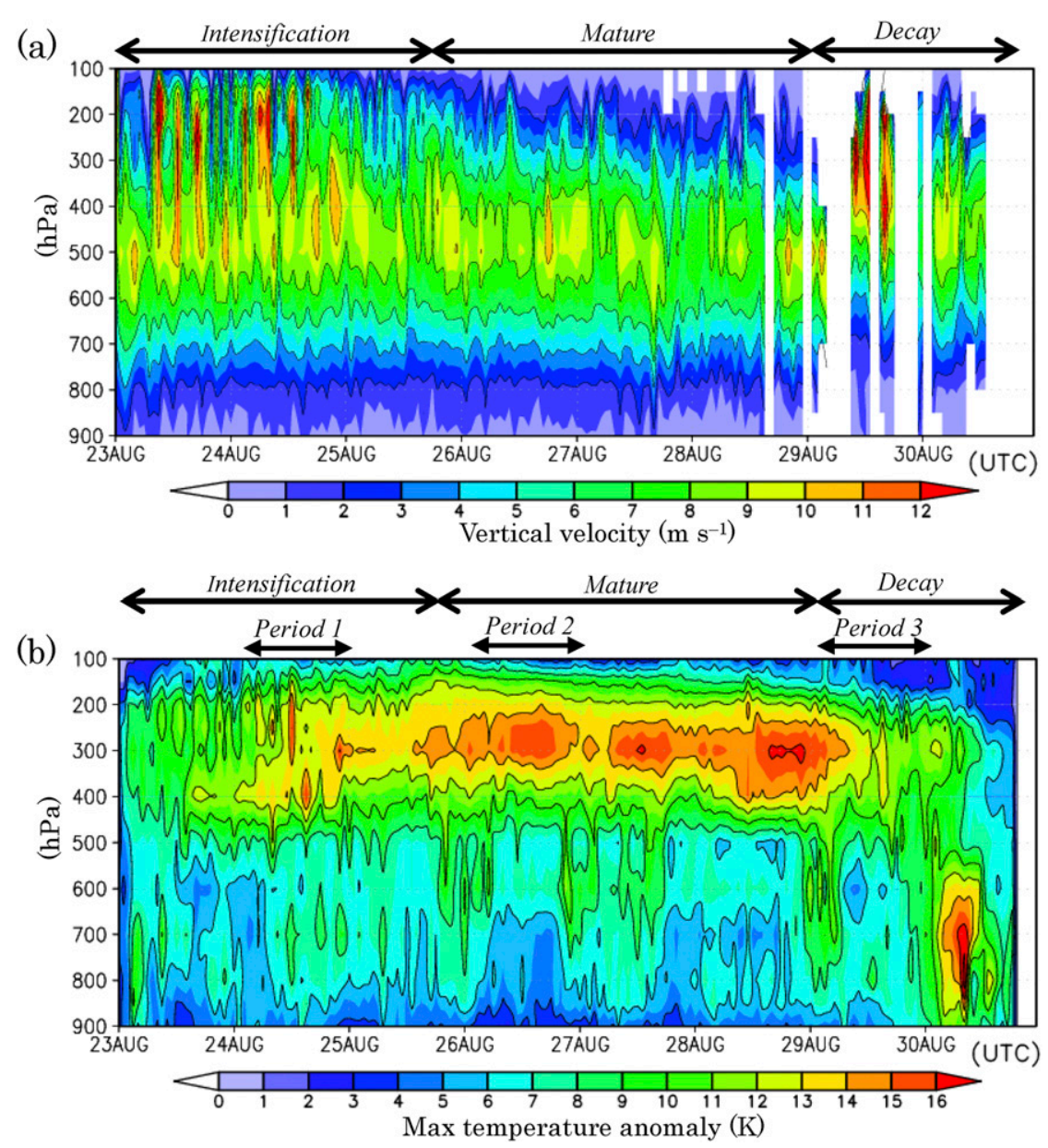

FIG. 3. Time-height cross sections of (a) mean vertical velocity for CB area (color scale and contours; $\mathrm{m} \mathrm{s}^{-1}$ ) within a radius of $3 \mathrm{RMW}$ and (b) maximum temperature anomaly (color scale and contours; K) within a radius of $200 \mathrm{~km}$ from the TC center in the simulated Typhoon Lionrock (2016).

between south and east in the early intensification phase. After that, it shifted to the directions between south and west. Finally, it turned to north during the decay phase. Noticeably, the upper-tropospheric wind speed was less than $5 \mathrm{~m} \mathrm{~s}^{-1}$ during the intensification phase (Fig. 2c), which indicates that the wind fields around Typhoon Lionrock did not significantly distort the $\mathrm{TC}$ wind and warm-core structures.

\section{c. Warm-core intensification associated with convective burst}

This subsection examines the relationship between warm-core intensification and deep convection. A timeheight cross section of the averaged vertical velocity for $\mathrm{CB}$ grids within a radius of $3 \mathrm{RMW}$ shows that peaks of updrafts corresponding to vigorous convection appeared at intervals shorter than one day (Fig. 3a). The updraft for $\mathrm{CB}$ grids tended to be maximized mainly in the midtroposphere except for the early intensification phase and 29 August 2016 (Fig. 3a) when the TC was accompanied by deep convection occurring within a narrow area $\left(<\right.$ approximately $70 \mathrm{~km}^{-2}$ ) before making landfall at the northeastern part of Japan (Wada and Oyama 2018). The maximum updraft within a radius of $3 \mathrm{RMW}$ at $500 \mathrm{hPa}$ level for $\mathrm{CB}$ grids reached about $11-12 \mathrm{~m} \mathrm{~s}^{-1}$.

The time-height cross section of the maximum temperature anomaly used to indicate the warm-core intensity (Fig. 3b) reveals two noticeable features. First, the height of the maximum temperature anomaly drastically changed depending on the phase. That is, the height of warm-core peak became higher as the TC develops, especially, the ascent is clear from 23 to 24 August, during the early intensification phase. In contrast, during the decay phase, the height of the warm core rapidly descended as updrafts became weaker than those during the 
mature phase, suggesting the importance of strong innercore updrafts in maintaining the upper-tropospheric warm core. Second, decreases in MSLP at around 00001800 UTC 25 August, 0000-1200 UTC 27 August, and 0000-1800 UTC 28 August (Fig. 2a) roughly corresponded to the increase of the temperature anomaly in the upper troposphere (Fig. 3b), indicating that the central pressure decreases with the development of the warm core. Among these warm-core developments, it should be noted that the maximum temperature anomaly at $300 \mathrm{hPa}$ level reaches its maximum at around 0000-1200 UTC 26 August (i.e., 6-18h after 1800 UTC 25 August 2016 when the central pressure reaches the lifetime minimum). One possible reason why the maximum temperature anomaly at $300 \mathrm{hPa}$ level was maximized after the central pressure reached its minimum is the elevation of warmcore height indicated by the elevation of the $6-12 \mathrm{~K}$ temperature anomaly contours on 25 August 2016 (Fig. 3b). This change in the warm-core structure could indicate that the atmospheric layer of the troposphere became thicker and is consistent with the previous studies based on satellite observations and numerical simulations (Oyama 2014; Ohno and Satoh 2015; Kieu et al. 2016).

To further examine the characteristics of the warmcore structure and eyewall, we focused on the spatial distributions of temperature anomaly at $300 \mathrm{hPa}$ level (Fig. 4) in three periods: Period 1, 0000-1800 UTC 24 August during the intensification phase; Period 2, 0000-1800 UTC 26 August during the mature phase; and Period 3, 0000-1800 UTC 29 August during the decay phase. During Period 1, the temperature anomaly gradually increased, with peak values around the TC center. The distribution of total precipitable water (TPW) during Period 1 shows that an eyewall with TPW greater than approximately $3 \mathrm{~g} \mathrm{~cm}^{-2}$ rapidly developed (figures not shown). During Period 2, the maximum temperature anomaly reaches a local maximum at around 1200 UTC 26 August just after the MSLP of the simulated Typhoon Lionrock reaches the lifetime minimum. It is noteworthy that the maximum temperature anomaly significantly increased within the TC eye, identified as the area surrounded by the eyewall with TPW $>3 \mathrm{~g} \mathrm{~cm}^{-2}$ (figures not shown).

Regarding this interpretation, since the influences of the mixing effect within the eyewall are an interest (Schubert et al. 1999; Kossin and Eastin 2001; Cram et al. 2007; Nguyen et al. 2011), we examined the horizontal distribution of vorticity at $700 \mathrm{hPa}$ level. The examination showed that the rotation greater than $7 \times 10^{-3} \mathrm{~s}^{-1}$ existed in the inner-edge of the eyewalls during 26-28 August 2016 (Fig. 5) when the positive temperature anomaly within the eye was greater than that outside the eye (i.e., the eyewall and outside it) (Fig. 4), which implies that large atmospheric mixing with the barotropic instability existed around the inner edge of the eyewall. These results suggest that there is some atmospheric mixing effect to make the radial temperature gradient between the eye and the eyewall less steep even when a distinct positive temperature anomaly existed within the eye. For discussing whether barotropic instability occurred around the inner edge of the eyewall, we computed the stability parameters, $\delta\left(=r_{1} / r_{2} ; r_{1}\right.$ and $r_{2}$ are the radii of the inner and outer edges of a high-rotation annular area) and $\gamma\left[=\left(\xi_{1}+\xi_{2}\right) / \zeta_{\text {av }} ; \xi_{1}+\xi_{2}\right.$ : average rotation for radius $<r_{1}, \xi_{2}$ : average rotation between $r_{1}$ and $r_{2}, \zeta_{\text {av: }} \xi_{1} \delta^{2}+\xi^{2}$ ], which are based on a simple barotropic model (Schubert et al. 1999). The examination for the rotation fields at $700 \mathrm{hPa}$ level from 26 August 2016 to 28 August 2016 (Fig. 5) showed that $\delta$ is $0.75-0.8$ and $\gamma$ is $0.8-0.85$, suggesting that barotropic instability possibly occurred near the inner edge of the high-rotation area. However, further discussion is necessary in the future study because this simulation was performed by the nonhydrostatic atmospheric model. The relationship between the increase of the positive temperature anomalies and downdrafts within the eye is examined in section $4 \mathrm{e}$.

During Period 3 when the TC was decaying and the warm core rapidly weakened and descended, the maximum temperature anomaly within the eye decreased and the area of the positive temperature anomaly shrank with the dissipation of the eyewall. It should be noted that the warm-core weakening corresponded well to the drop of SST (Fig. 2b) and the increase of uppertropospheric wind speed from 5 to $10 \mathrm{~m} \mathrm{~s}^{-1}$ or greater (Fig. 2c), suggesting that the environmental winds and oceanic environment likely have negatively influenced the warm-core intensity and structure.

Figure 6a compares the variations in the maximum temperature anomaly at $300 \mathrm{hPa}$ level with those in the mean vertical velocities for $\mathrm{CB}$ grids at $500 \mathrm{hPa}$ level. It is found that most of the local maxima in the temperature anomaly corresponded to those in the updrafts for $\mathrm{CB}$ grids with a lag time. The lag correlation analysis showed that the warm-core maximum temperature anomaly developed approximately $0-12 \mathrm{~h}$ after the updraft at $500 \mathrm{hPa}$ level for CB grids increase. The correlation coefficient is $0.59-0.63$ for the lag times from 0 to $12 \mathrm{~h}$. The significance is high according to the $P$ values $\left(7.8 \times 10^{-10}-2.5 \times 10^{-9}\right)$. This result implies that the warm core developed in association with the $\mathrm{CBs}$, which released diabatic heat within the eyewall. The convection deepening prior to the warmcore development seen in the simulation is consistent with an observational study using the temperature fields from the observations of AMSU-A microwave sounder on board NOAA and MetOp series polar orbital satellites and Himawari-8 infrared band (Oyama et al. 2018). 
Period 1

0000 UTC 24 August

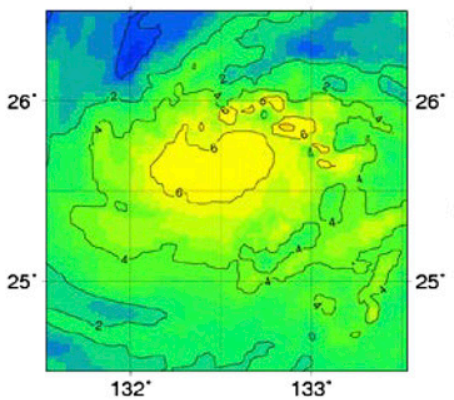

0600 UTC 24 August

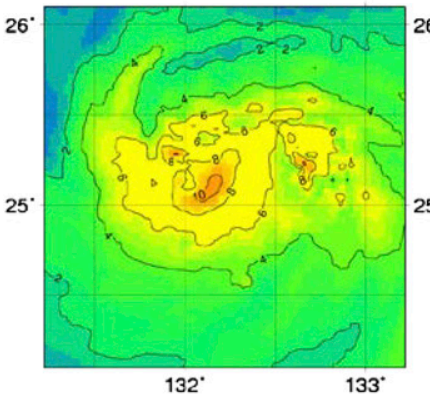

1200 UTC 24 August

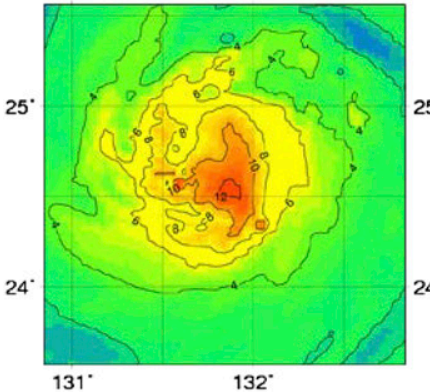

1800 UTC 24 August

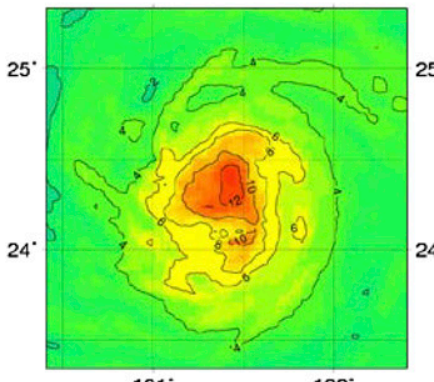

132
Period 2

0000 UTC 26 August

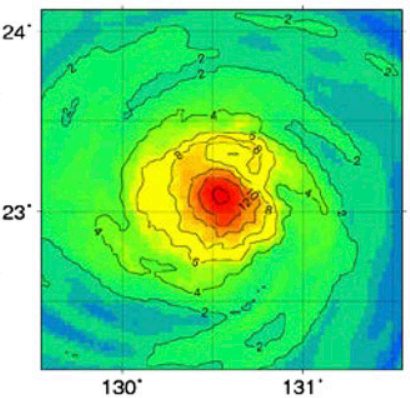

0600 UTC 26 August

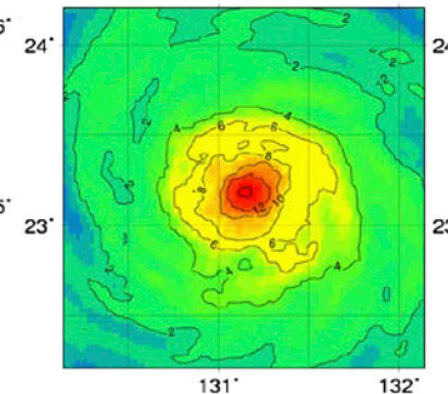

1200 UTC 26 August

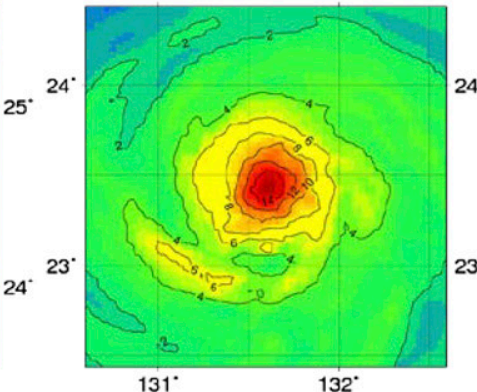

1800 UTC 26 August

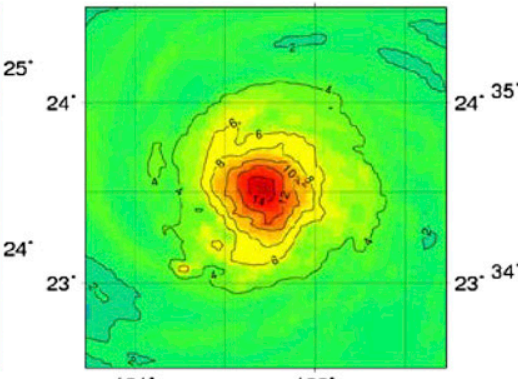

$131^{\circ}$
Period 3

0000 UTC 29 August

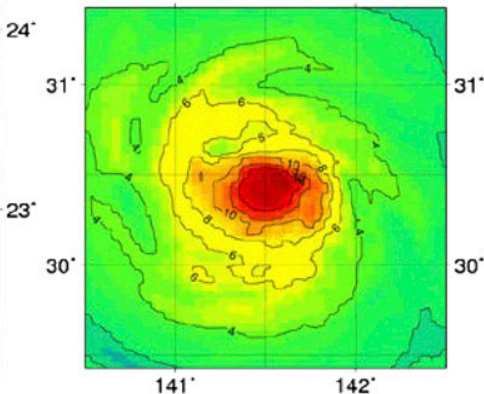

0600 UTC 29 August

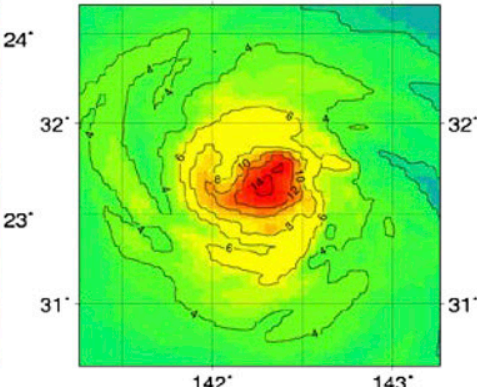

1200 UTC 29 August

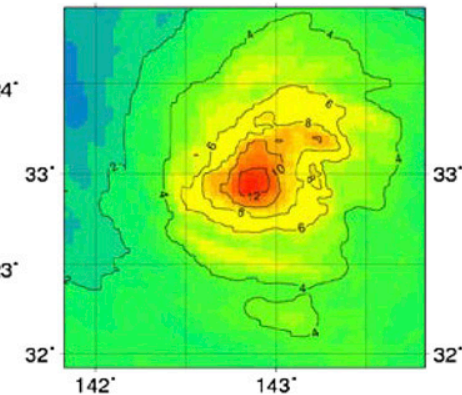

1800 UTC 29 August

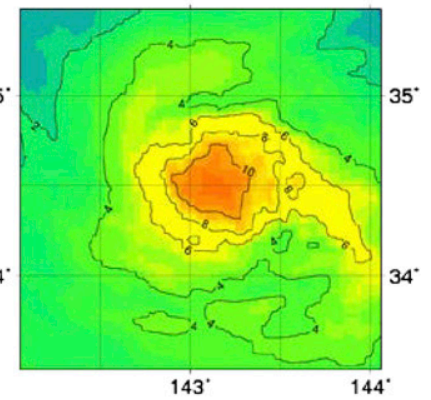

$143^{\circ}$

$\begin{array}{lllllllllll}-2 & 0 & 2 & 4 & 6 & 8 & 10 & 12 & 14 & 16\end{array}(\mathrm{~K})$

FIG. 4. Spatial distributions of the temperature anomaly (color scale; K) at $300 \mathrm{hPa}$ in an area of $2^{\circ}$ longitude $\times$ $2^{\circ}$ latitude on the center of the simulated Typhoon Lionrock (2016) during Periods 1, 2, and 3 (see Fig. 3b). 

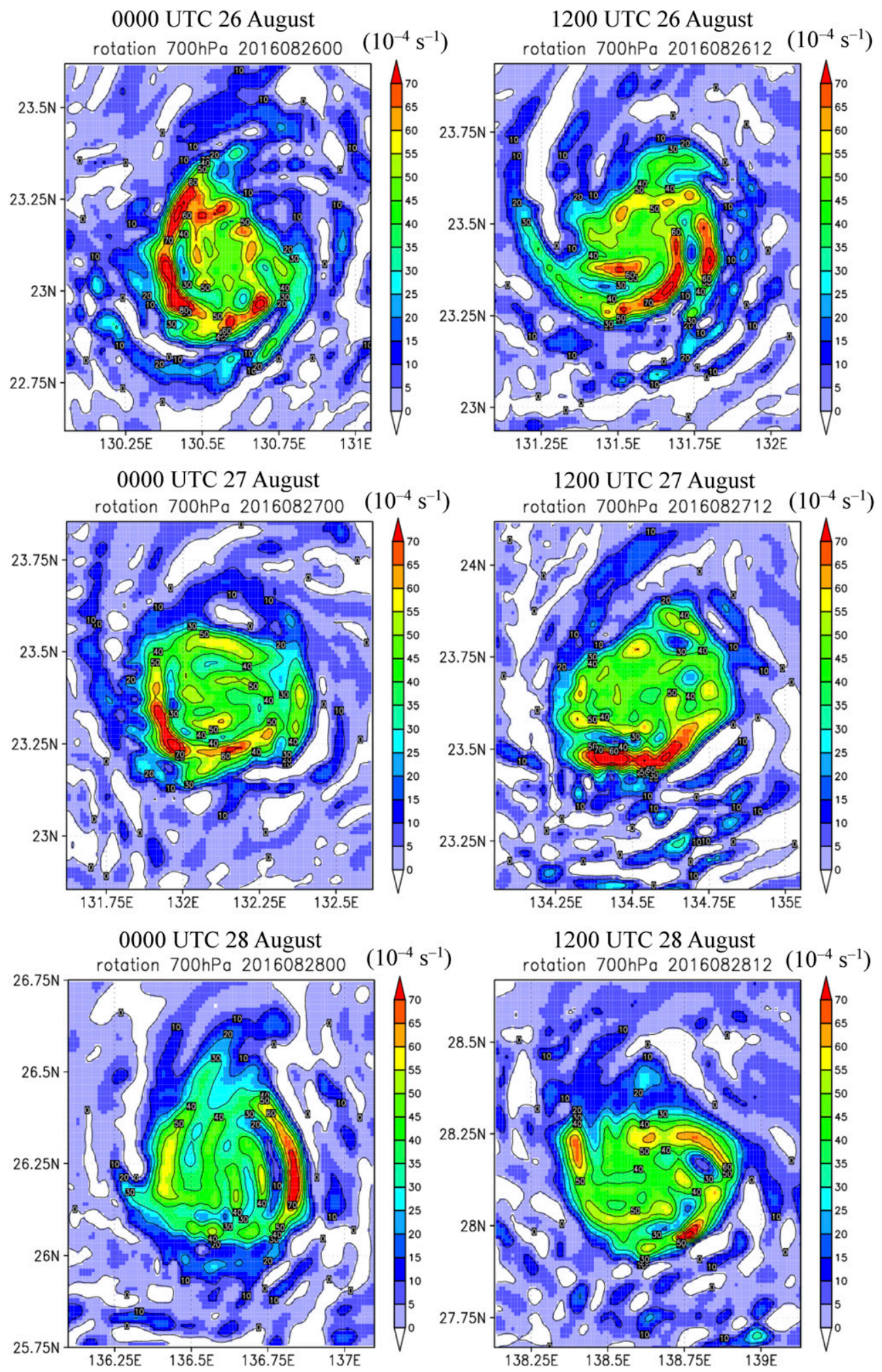

FIG. 5. Spatial distributions of rotation at $700 \mathrm{hPa}$ level (unit: $10^{-4} \mathrm{~s}^{-1}$ ) in an area of $1^{\circ}$ longitude $\times$ $1^{\circ}$ latitude on the center of the simulated Typhoon Lionrock (2016) from 0000 UTC 26 Aug to 1200 UTC 28 Aug 2016. The TC center is at the center of each panel. 

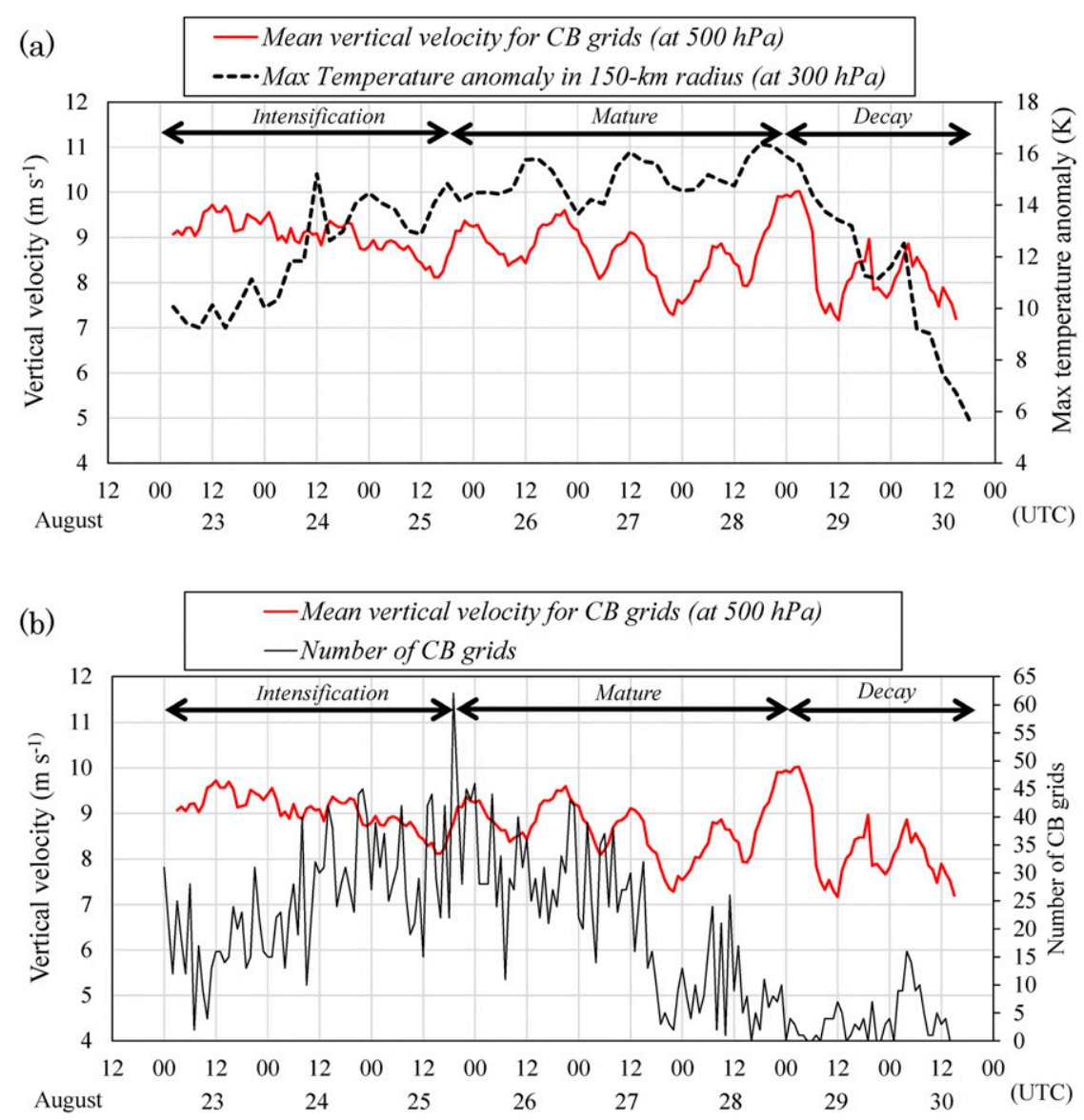

FIG. 6. (a) Time series of the maximum temperature anomaly at $300 \mathrm{hPa}$ level within $200 \mathrm{~km}$ radius (black dashed line) and mean vertical velocity at $500 \mathrm{hPa}$ (red solid line) for $\mathrm{CB}$ grids within a radius of $3 \mathrm{RMW}$ from the TC center, and (b) time series of the number of CB grids and mean vertical velocity at $500 \mathrm{hPa}$ level for $\mathrm{CB}$ grids within a radius of $3 \mathrm{RMW}$ in the simulation of Typhoon Lionrock (2016).

Figure $6 \mathrm{~b}$ shows the number of $\mathrm{CB}$ grids in comparison with the mean updrafts for $\mathrm{CB}$ grids within a radius of 3RMW at $500 \mathrm{hPa}$ level. Notably, the number of $\mathrm{CB}$ grids is not linear to the magnitude of the updraft for $\mathrm{CB}$ grids although parts of the local maxima corresponded to the local maximum of the updrafts. The number of CB grids gradually increased with a $2-3$-h period variation during the intensification phase; after that, it decreased during the mature and decay phases.

Figure 7 shows the spatial distributions of $\mathrm{CB}$ grids in an area of $2^{\circ} \times 2^{\circ}$ which is centered on the TC center during Periods 1, 2, and 3. Noticeably, the azimuthal and radial distributions of $\mathrm{CB}$ grids within the TC inner core were different between the periods. During period 1, the $\mathrm{CB}$ grids tended to appear in the eastern side to the TC center at 0000 UTC 24 August, subsequently, they were inclined to the southern sector. During Period 2, CB grids appeared in the southern side during the entire period. It should be noted that the $\mathrm{CB}$ grids for Period 2 tended to be located closer to the TC center than that for Period 1, indicating the eyewall radius for Period 2 became smaller than that for Period 1. During Period 3, the number of $\mathrm{CB}$ grids was quite smaller than that for Periods 1 and 2, and the distances between the $\mathrm{CB}$ grids and the TC center became larger than that for Periods 1 and 2 .

Figure 8 compares the locations of CBs with maximum vertical velocity and the VWS. Noticeably, the change in the angle of maximum vertical velocity tended to be synchronous with the change in the VWS direction, which suggests that VWS increases the secondary circulation on the downshear left side (Ueno 2007) and enhanced the updrafts associated with CBs.

Regarding the warm-core intensification, we also revealed that the maximum tangential wind $V_{\text {max }}$ increased at $300 \mathrm{hPa}$ level when the temperature anomaly increased 
Period 1

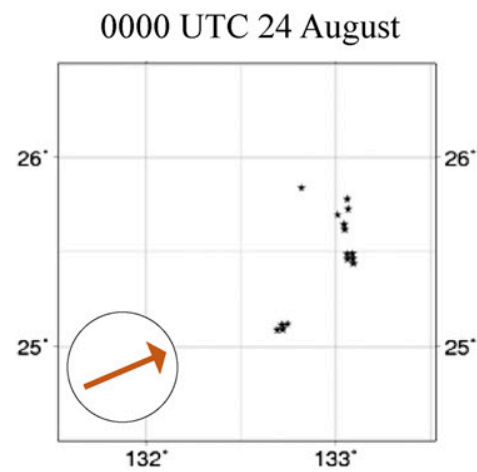

0600 UTC 24 August

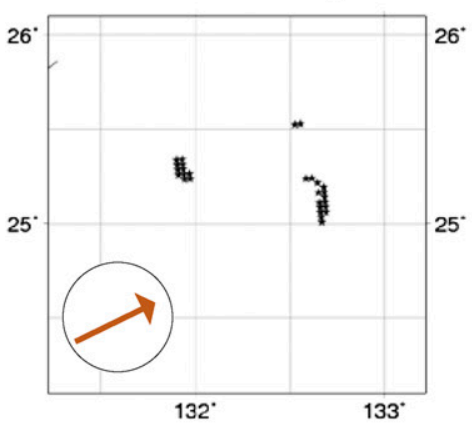

1200 UTC 24 August

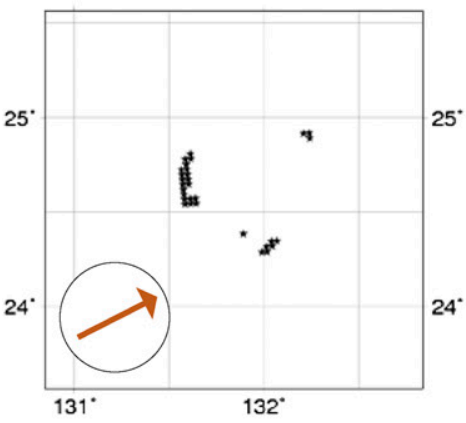

1800 UTC 24 August

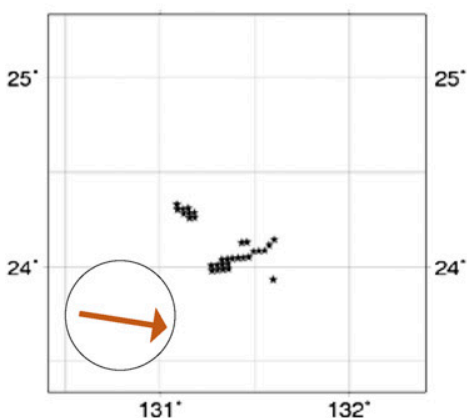

Period 2

0000 UTC 26 August

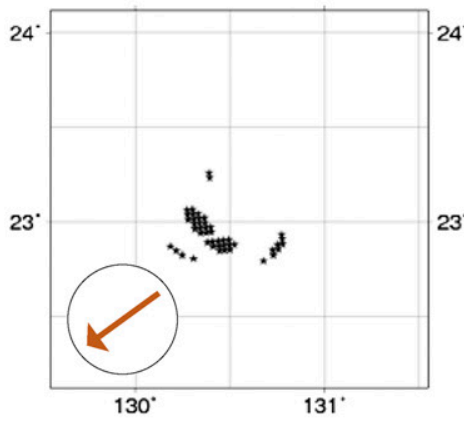

0600 UTC 26 August

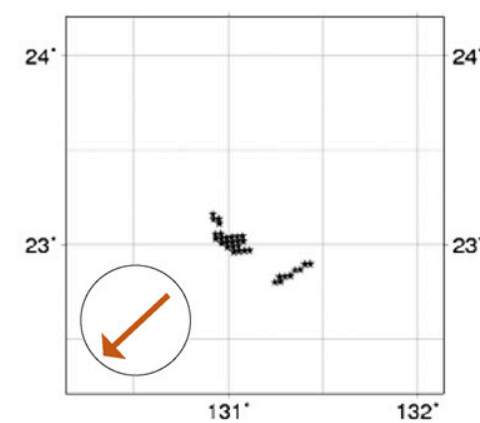

1200 UTC 26 August

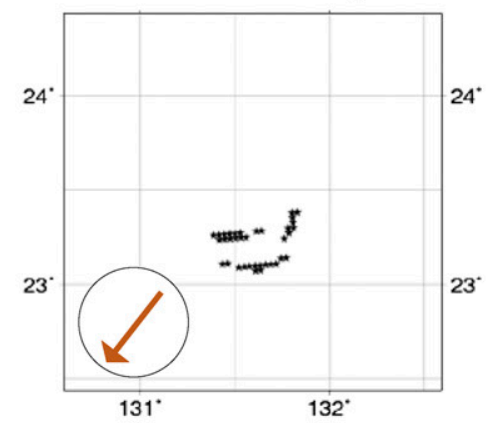

1800 UTC 26 August

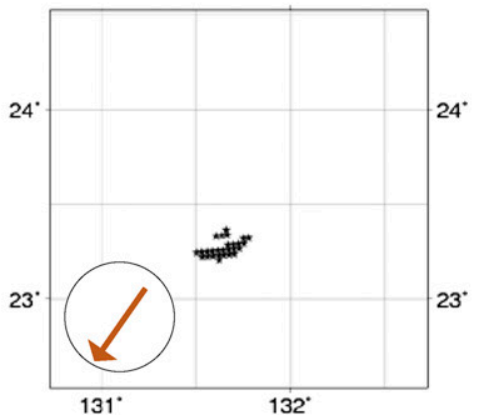

Period 3

0000 UTC 29 August

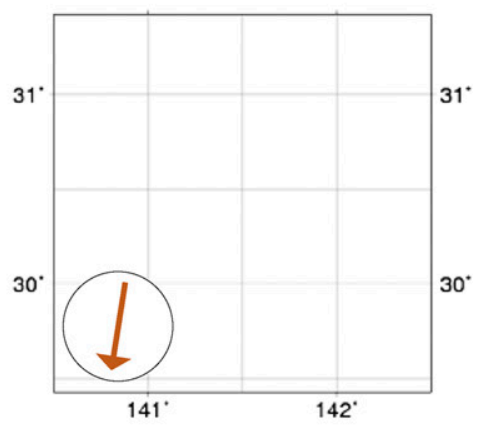

0600 UTC 29 August

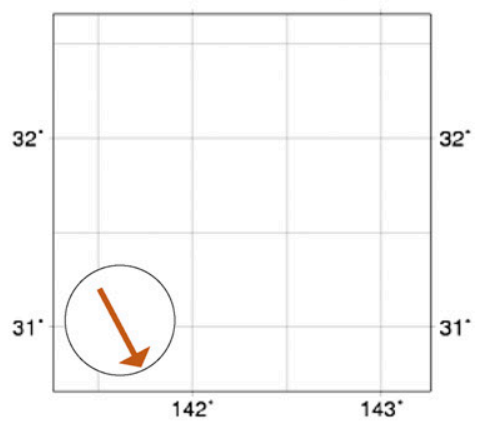

1200 UTC 29 August

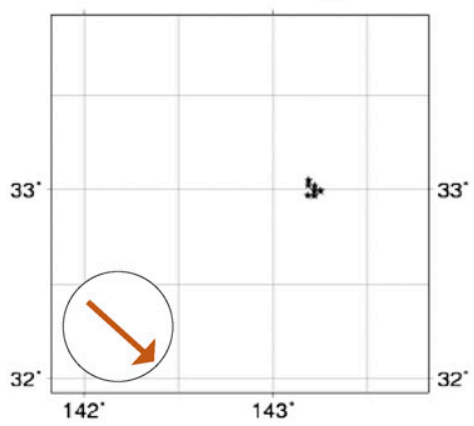

1800 UTC 29 August

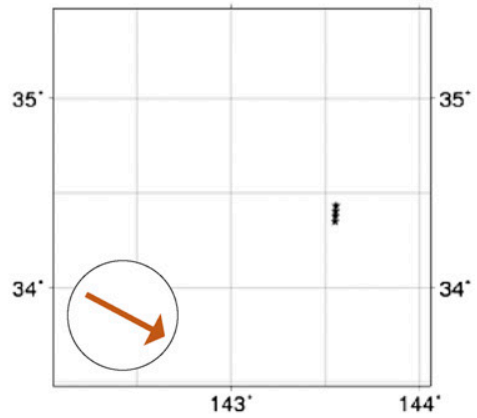

FIG. 7. Spatial distributions of $\mathrm{CB}$ grids in an area of $2^{\circ}$ longitude $\times 2^{\circ}$ latitude on the center of the simulated Typhoon Lionrock (2016) during Periods 1, 2, and 3 (see Fig. 3b). The TC center is at the center of each panel. The arrow in each panel indicates the direction of VWS. 


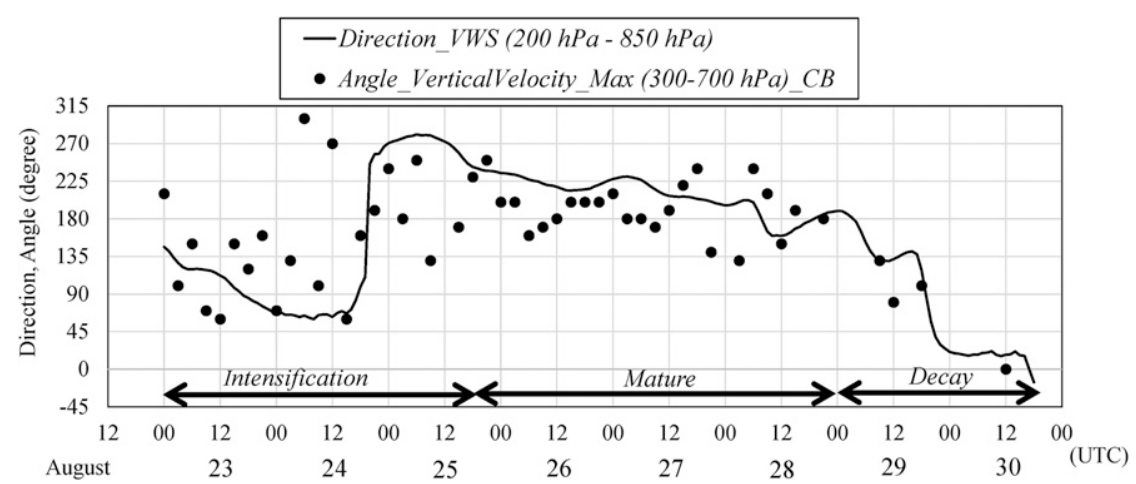

FIG. 8. The angle of the maximum of mean vertical velocity for $\mathrm{CB}$ grids between 700 and $300 \mathrm{hPa}$ levels (filled circles) with reference to the center of the simulated Typhoon Lionrock (2016), and the direction of mean vertical wind shear (VWS) between 200 and $850 \mathrm{hPa}$ levels within a radius of $600 \mathrm{~km}$ (solid line). Directions and angles of $0^{\circ}, 90^{\circ}, 180^{\circ}$, and $270^{\circ}$ denote north, east, south, and west, respectively.

(figures not shown). The lag correlations between the tendency of $V_{\max }$ (referred to as $d V_{\max } / d t$ ) in the lower troposphere and those in the mid- to high troposphere indicated that $d V_{\max } / d t$ at $700 \mathrm{hPa}$ level tended to lead $d V_{\max } / d t$ at $200-600 \mathrm{hPa}$ levels within a lag time of $0-2 \mathrm{~h}$. The relatively high correlations suggest that the primary cyclonic circulation developed vertically via the transport of the absolute angular momentum from the surface to the upper troposphere (Sawada and Iwasaki 2007; Bryan and Rotunno 2009). This result may also imply that deep convection and resultant diabatic heat release around the high inertial stability area (i.e., within the radius of maximum wind), favors the warm-core development (Vigh and Schubert 2009). The relatively high correlation between the warm-core development and the increase in the cyclonic circulation in the upper troposphere is consistent with an observational study using the temperature fields from the observations of AMSU-A satellite microwave sounder and the tangential winds near the cloud top obtained from atmospheric motion vectors derived from Himawari-8 imagery (Oyama et al. 2018). It is also possible that the updrafts within the TC inner core generate heat that deepens the pressure and increases the radial inflow, which then increases the tangential wind through horizontal inward transport of angular momentum both at lower levels (where inflow is maximized) and in the weak inflow aloft. Evidence for this process is present in the weak radial inflows with magnitudes of $0.1-1 \mathrm{~m} \mathrm{~s}^{-1}$ existing at $500-850 \mathrm{hPa}$ levels in the radii of $50-250 \mathrm{~km}$ during 0600-1800 UTC 28 August 2016 (figures not shown). Determining the contribution of these processes to warm-core intensification could lead to greater insight into this phenomenon. However, this is beyond the scope of this study.

\section{d. Budget analysis of potential temperature for assessing the warm-core intensification process}

In this subsection, we examine the budgets of potential temperature (PT) within the TC inner core using Eq. (1):

$$
\frac{\partial \theta}{\partial t}=\nabla \theta \cdot \mathbf{V}+\mathrm{DH}
$$

In Eq. (1), $\theta$ is PT $(\mathrm{K}), \mathbf{V}$ is three-dimensional wind vector $\left(\mathrm{m} \mathrm{s}^{-1}\right)$, and $\mathrm{DH}$ is diabatic heating $\left(\mathrm{Kh}^{-1}\right)$. The left side term is the tendency of PT (hereafter PPT; $\mathrm{Kh}^{-1}$ ), and the first term on the right side represents the advection of $\theta$.

Figures 9-11 show the radius-height cross sections of the budget analysis results by Eq. (1) for Period 1, 2, and 3, respectively (Fig. 3b). As seen in section 4c, Period 1 is the period when the height of the warm-core peak gradually ascended from 400 to $300 \mathrm{hPa}$ level (Fig. 3b). The PPT during Period 1 is high in the radii of $10-40 \mathrm{~km}$ (Fig. 9a) where the mean upward motion is greater than $0.5 \mathrm{~m} \mathrm{~s}^{-1}$ from the surface to the tropopause (figures not shown). The distribution of PPT is similar to that of diabatic heat (Fig. 9b) except for near the tropopause at approximately $100-80 \mathrm{hPa}$. In contrast, PT advection within a radius of about $70 \mathrm{~km}$ tended to be negative (Fig. 9c), indicating the low PT air was transported from the lower troposphere to the upper troposphere. The positive value of diabatic heat within a radius of 10 $20 \mathrm{~km}$ indicates that diabatic heat from the deep convection which is inferred by the upward motion was advected or was diffused toward the TC center.

During Period 2, the warm-core peak reached the $300 \mathrm{hPa}$ level and the TC was transforming into the mature stage. The temperature anomaly within the TC eye became greater than that outside it. The PPT and 
(a)

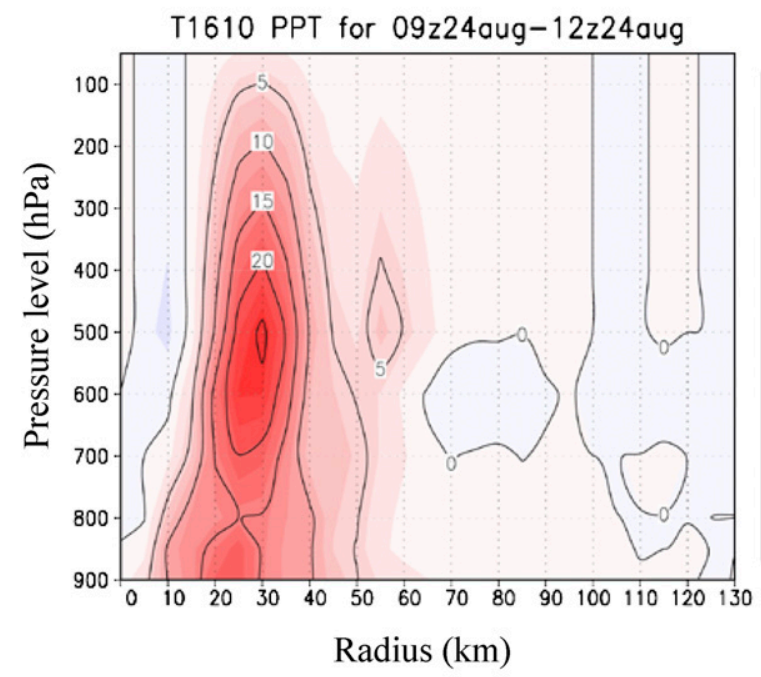

(c)

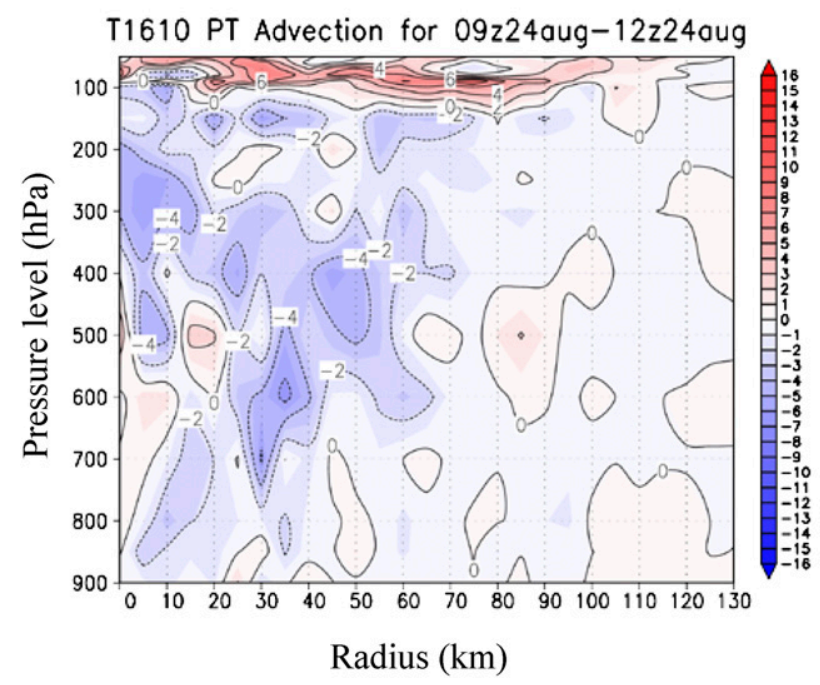

diabatic heat within the eyewall became greater than those during Period 1 (Figs. 9 and 10). Corresponding to the increases in PPT and diabatic heat (Figs. 10a,b), the updrafts within the eyewall became stronger and limited within the radii of $10-35 \mathrm{~km}$ (figures not shown). It should be noted that the PT advection was positive with a downward motion of $0-0.5 \mathrm{~m} \mathrm{~s}^{-1}$ within a radius of $5 \mathrm{~km}$ from the surface to the tropopause height (Figs. 10c,d), indicating the subsidence of high-PT air within TC eye.

During Period 3 when the warm-core intensity became weak and the height of the warm core gradually descended, the maximum PPT within the eyewall decreased to $10-15 \mathrm{~K} \mathrm{~h}^{-1}$ (Fig. 11a), which is smaller than those for Period 1 and 2. The small magnitude of PPT for Period 3 (b)

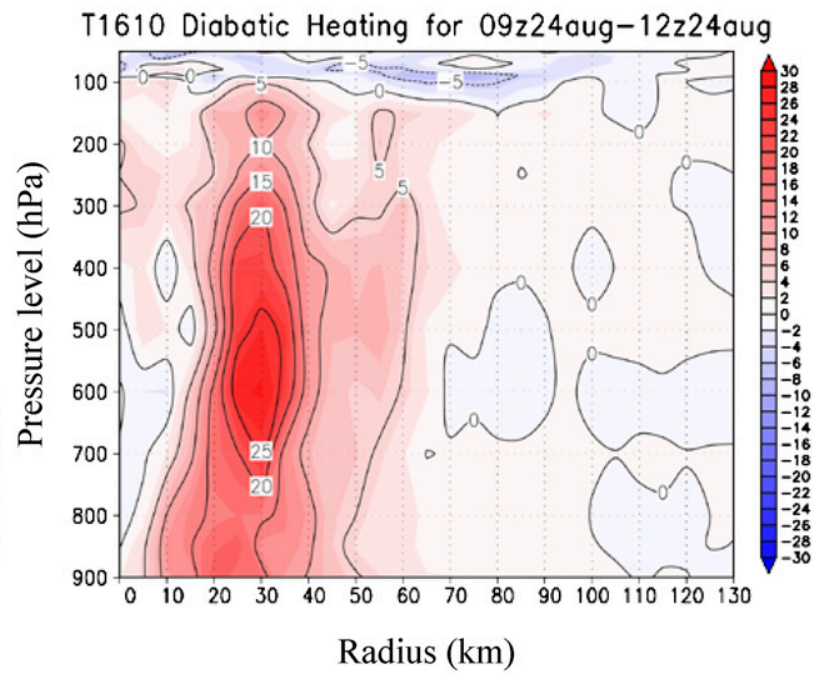

FIG. 9. Budget analysis of potential temperature (PT) within the inner core of Typhoon Lionrock (2016) in the simulation for 0900-1200 UTC 24 Aug 2016 in Period 1. (a) The tendency of PT, (b) diabatic heat term, and (c) PT advection term. The unit is $\mathrm{Kh}^{-1}$. is due to the small magnitude of diabatic heat (Fig. 11b) which is related to weak updrafts within the eyewall (figures not shown).

\section{e. Influence of subsidence within TC eye on warm-core intensification}

In this subsection, we investigate the influence of subsidence within the eye, on warm-core intensification in the simulation. For this purpose, we define the TC eye as the area where the cloud water content (CWC) at $300 \mathrm{hPa}$ is less than $1.0 \times 10^{-5} \mathrm{~g} \mathrm{~kg}^{-1}$ within $50 \mathrm{~km}$ of the TC center, and the mean downdraft velocity within the eye (referred to as "eye downdraft") is the averaged velocity of the 10 largest downdrafts within the TC eye. Interestingly, as seen in Fig. 12a, peak temperature 
(a)

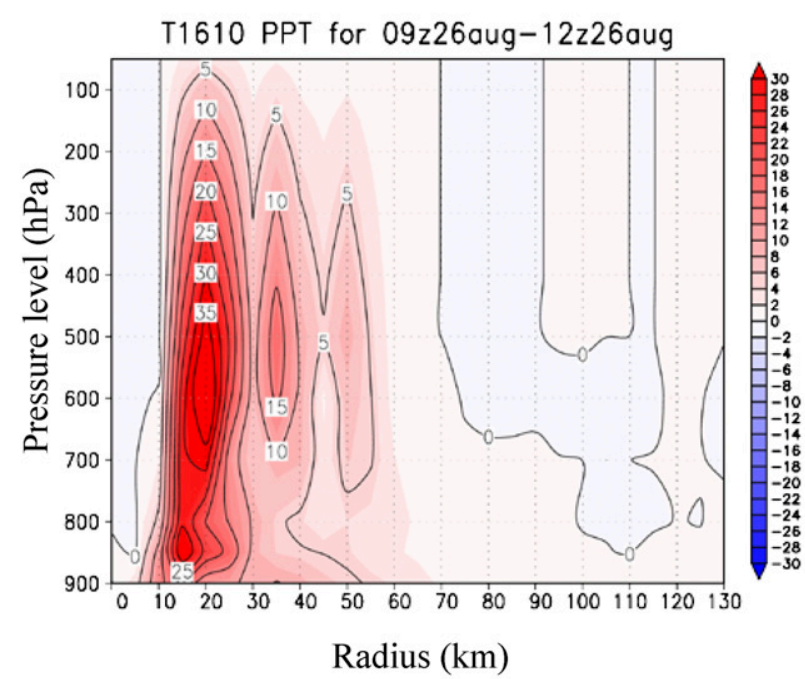

(c)

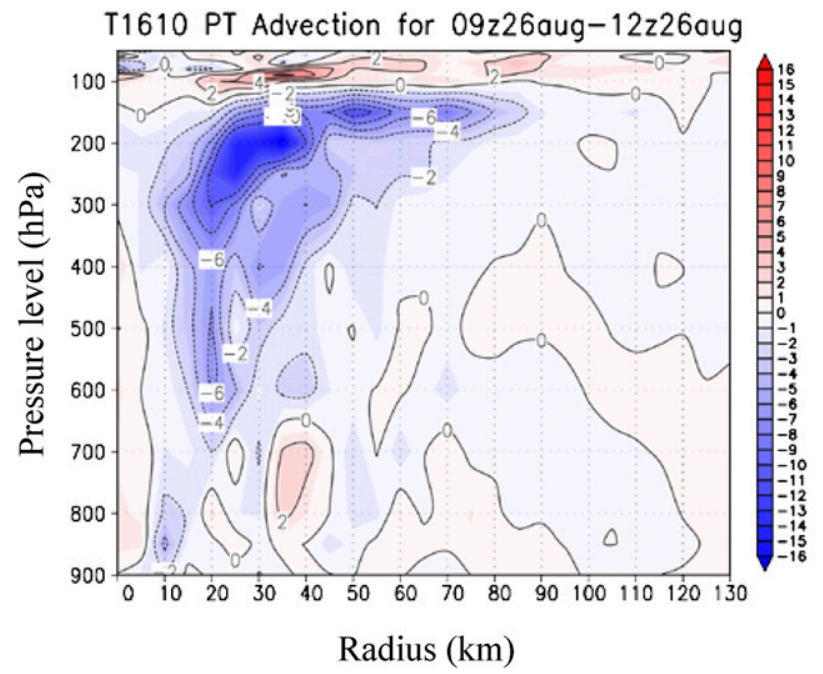

(b)

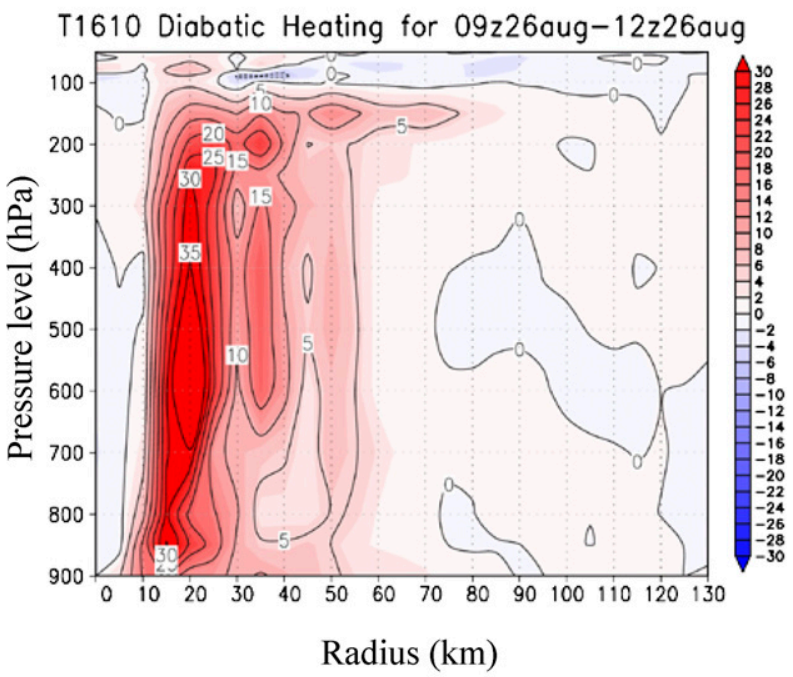

FIG. 10. As in Fig. 9, but for 0900-1200 UTC 26 Aug 2016 in Period 2. anomalies at $300 \mathrm{hPa}$ tended to follow the peak magnitudes of the eye downdrafts at 100,150,200, and $250 \mathrm{hPa}$ with a lag time of about $6-12 \mathrm{~h}$. The lag correlations also indicated that the temperature anomaly at $300 \mathrm{hPa}$ tended to increase approximately $0-12 \mathrm{~h}$ after the eye downdraft increases although the magnitude of correlation coefficient was not large $(0.23-0.29$ for the lag times from 0 to $12 \mathrm{~h}$ ). This result suggests a positive feedback between adiabatic heating due to the downdraft and increased temperature anomalies within the eye although the significance of the correlation is relatively low (the $P$ value is $2.6 \times 10^{-2}-7.1 \times 10^{-2}$ ).

To further examine the relationship between the increases of the maximum temperature anomaly within the eye and eye downdrafts, we sought the altitude of origin for the descending air using a time-height cross section of the eye downdrafts (Fig. 12b). Noticeably, parts of the peak eye downdrafts at around $50 \mathrm{hPa}$ level tended to be followed by peak eye downdrafts between 250 and $450 \mathrm{hPa}$, indicating that the air within the eye descended from near the tropopause, at around $50 \mathrm{hPa}$ level, where the vertical gradient of the potential temperature (PT) was large positive value (Figs. 13-14).

The PT budget analysis focusing on the TC eye and the eyewall (radius $<50 \mathrm{~km}$ ) indicated the eye development process was associated with subsidence within the eye during Period 1 and 2 (Fig. 15). For Period 1, the positive PT advection was found within the radius of $20 \mathrm{~km}$ from the TC center. It should be noted that the 
(a)

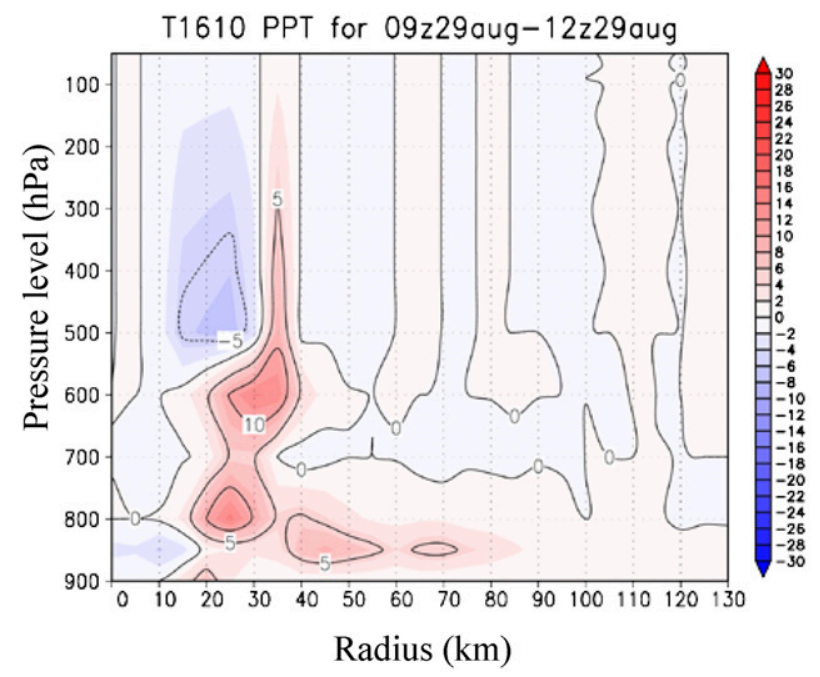

(c)

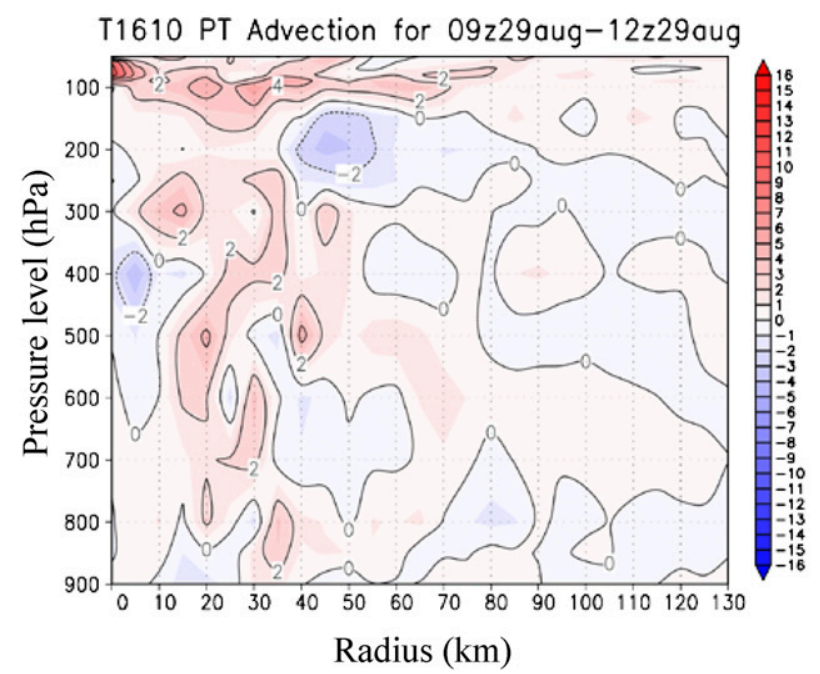

maximum peak of the positive PT advection greater than $10 \mathrm{~K} \mathrm{~h}^{-1}$ appeared around $500 \mathrm{hPa}$ level (the left panel of Fig. 15a), which was located just below the relatively strong downdraft (the right panel of Fig. 15a). For Period 2, the positive PT advection appeared within the radius of about $10 \mathrm{~km}$ (the left panel of Fig. 15b) which corresponded to the inner edge of the eyewall with the upward motion (the right panel of Fig. 15b).

Structural changes of the warm core during Periods 1 and 2 (section $4 \mathrm{c}$ ) are here re-examined in vertical PT and temperature anomaly cross sections at the TC center (Figs. 13 and 14). During both periods, peak temperature anomalies at $300 \mathrm{hPa}$ occurred at around $1200-1800$ UTC (Fig. 12a). During Period 1, when the magnitude of eye downdrafts rapidly increased and the temperature (b)

T1610 Diabatic Heating for 09z29aug-12z29aug

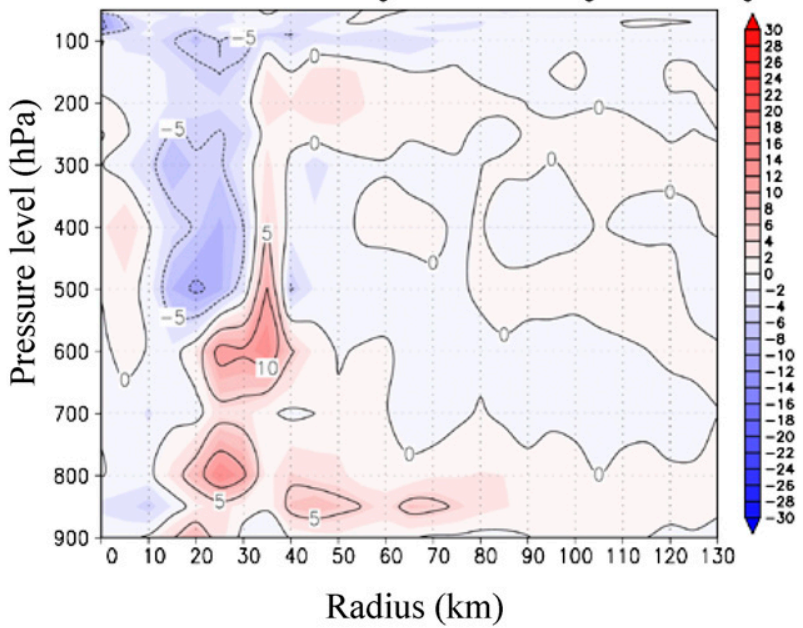

FIG. 11. As in Fig. 9, but for 0900-1200 UTC 29 Aug 2016 in Period 3.

anomaly increased, the $350-355 \mathrm{~K}$ PT contours descended to around the $400 \mathrm{hPa}$ level (Fig. 13a); the downward intrusions of the PT contours were distinct during 0000-0600 UTC 24 August (Figs. 13a, b). This indicates the intrusion of high-PT air from near the tropopause into the eye by the rapid increase of eye downdrafts. After continuous eye downdrafts, finally, $365 \mathrm{~K}$ PT contour reached the $300 \mathrm{hPa}$ level during 1200 1800 UTC. We note that the lag time of $6-12 \mathrm{~h}$ between the distinct downward intrusion of the $350-355 \mathrm{~K}$ PT contours and peak temperature anomalies seen in Period 1 is similar to the lag time between the peak eye downdrafts and peak temperature anomalies obtained from the time series of the maximum temperature anomalies and eye downdrafts (Fig. 12a) (i.e., 0-12 h). 
(a)

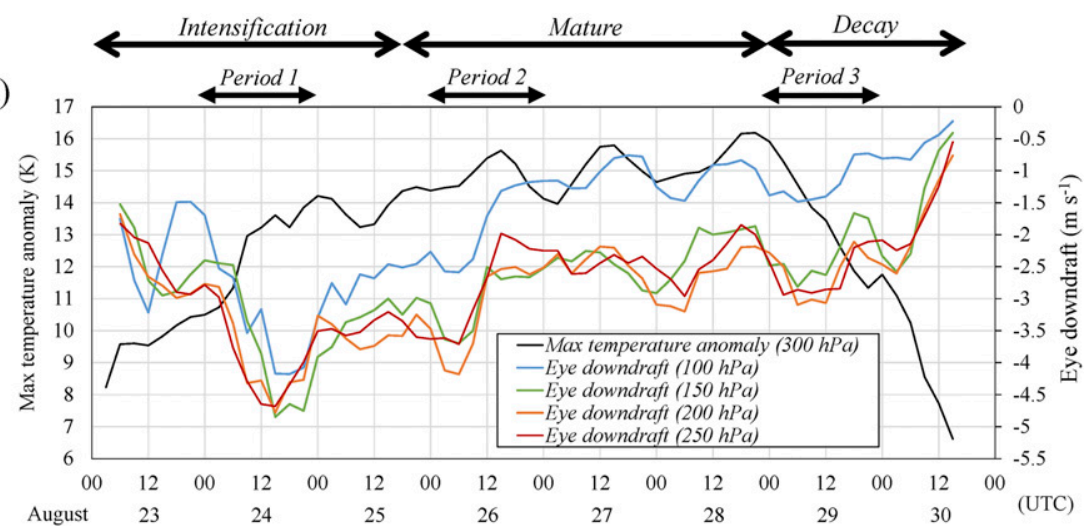

(b)

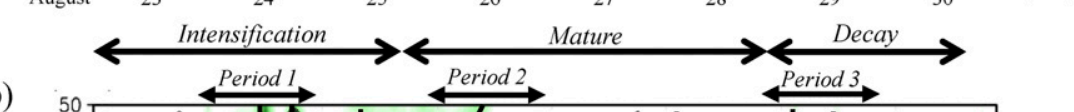

(c)

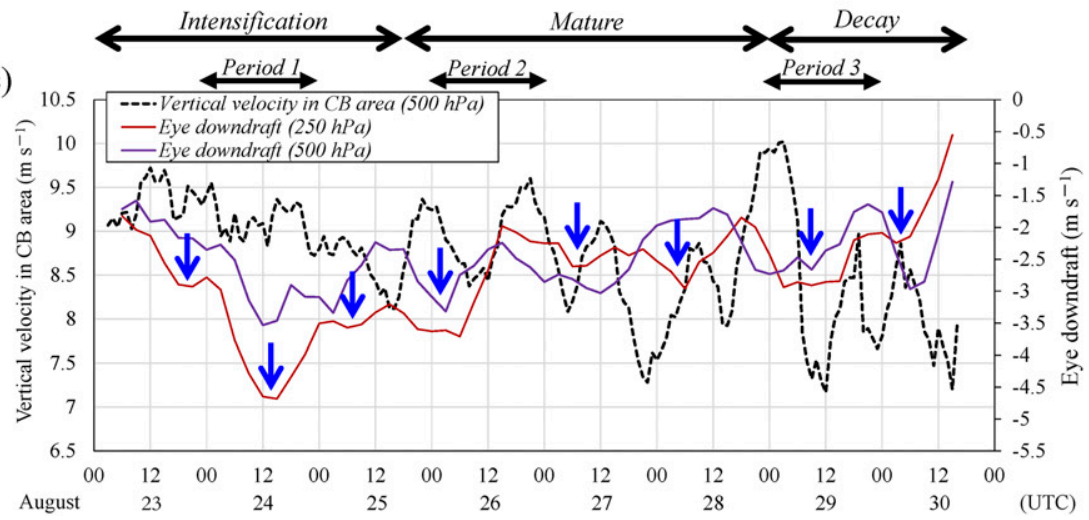

FIG. 12. (a) Time series of the maximum temperature anomalies at $300 \mathrm{hPa}$ (black line) and the averages of the 10 strongest downdrafts within the TC eye ("eye downdraft") at 100 (blue), 150 (green), 200 (orange), and 250 (red) hPa levels; (b) the time-height cross section of eye downdraft (color scale; $\mathrm{m} \mathrm{s}^{-1}$ ) and the maximum temperature anomaly at each pressure level (contours at intervals of $1 \mathrm{~K}$ ); and (c) time series of the mean vertical velocity for $\mathrm{CB}$ within $3 \mathrm{RMW}$ radius (black dashed line) and eye downdrafts at 250 (red) and 500 (purple) hPa levels in the simulated Typhoon Lionrock (2016). The dashed black lines in (b) indicate the peak eye downdrafts. The blue arrows in (c) indicate the peaks of the eye downdrafts at $250 \mathrm{hPa}$ level.

During Period 2, when the temperature anomaly increased after a strong eye downdraft at $150-250 \mathrm{hPa}$ levels with a magnitude greater than $3.5-4 \mathrm{~m} \mathrm{~s}^{-1}$, a distinct downward intrusion of the PT contours was evident during 0000-0600 UTC 26 August (Figs. 14a,b). Similar to Period 1 , the temperature anomaly reached its maximum during 1200-1800 UTC, 6-12 h after the eye downdraft reached its peak (0000-0600 UTC 26 August). 
(a) $(\mathrm{hPo})$

1610 0000Z24Aug2016 PT

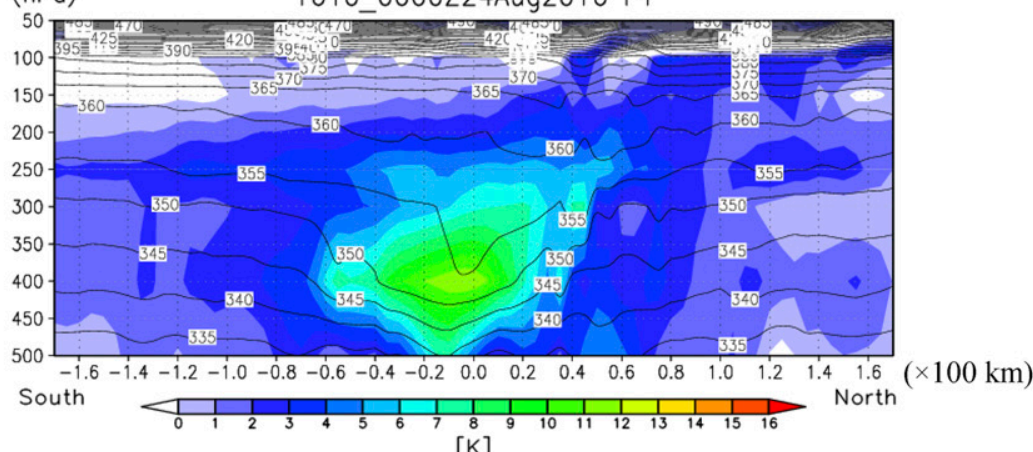

[K]

(b)

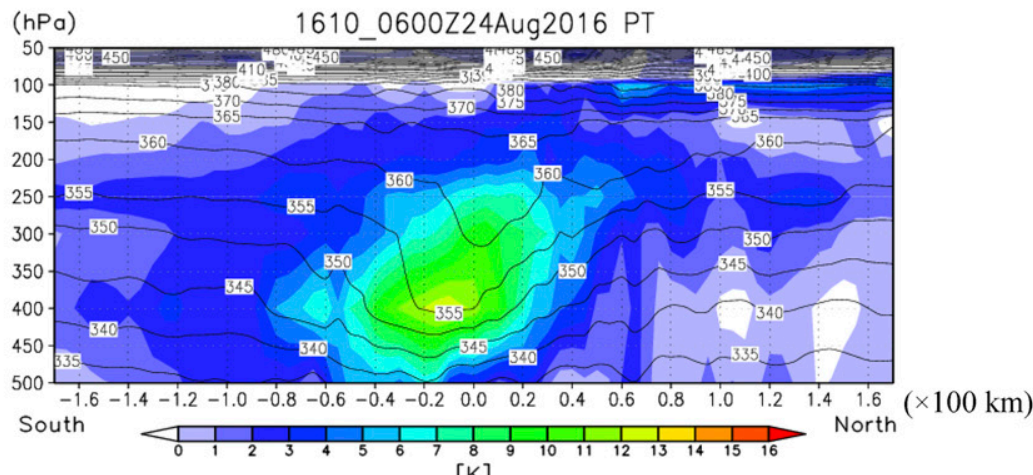

[K]

(c)
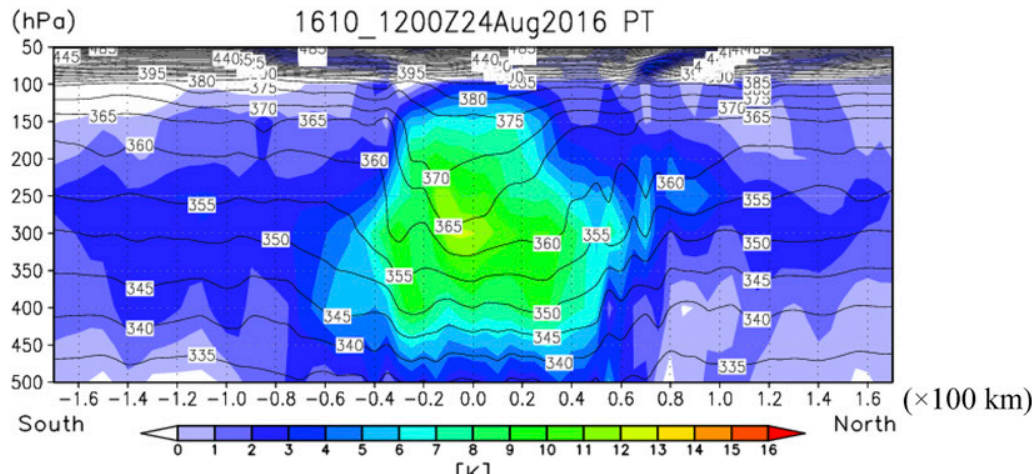

$[\mathrm{K}]$

(d)

(hPa) 1610_1800Z24Aug2016 PT

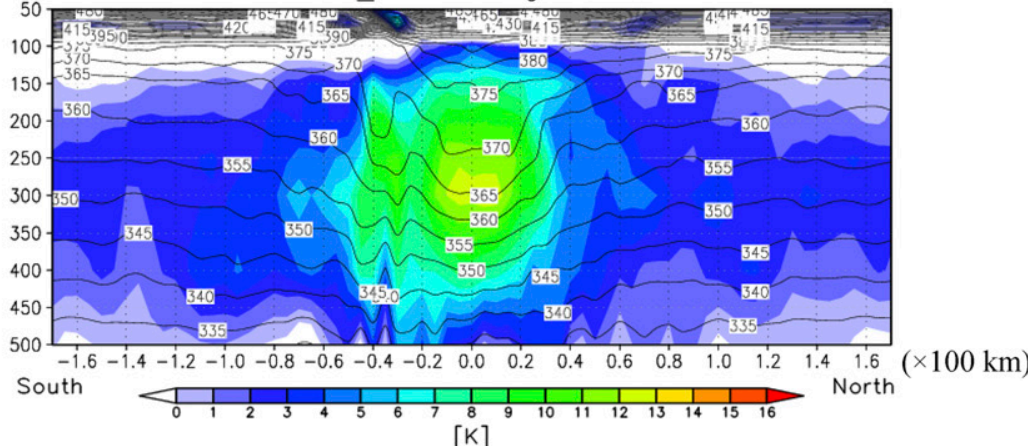

FIG. 13. North-south vertical cross sections of the temperature anomaly (color scale; K) and potential temperature (PT; contours at intervals of $5 \mathrm{~K}$ ) at the center of the simulated Typhoon Lionrock (2016) at (a) 0000, (b) 0600, (c) 1200, and (d) 1800 UTC 24 Aug 2016 (Period 1). 
(a)

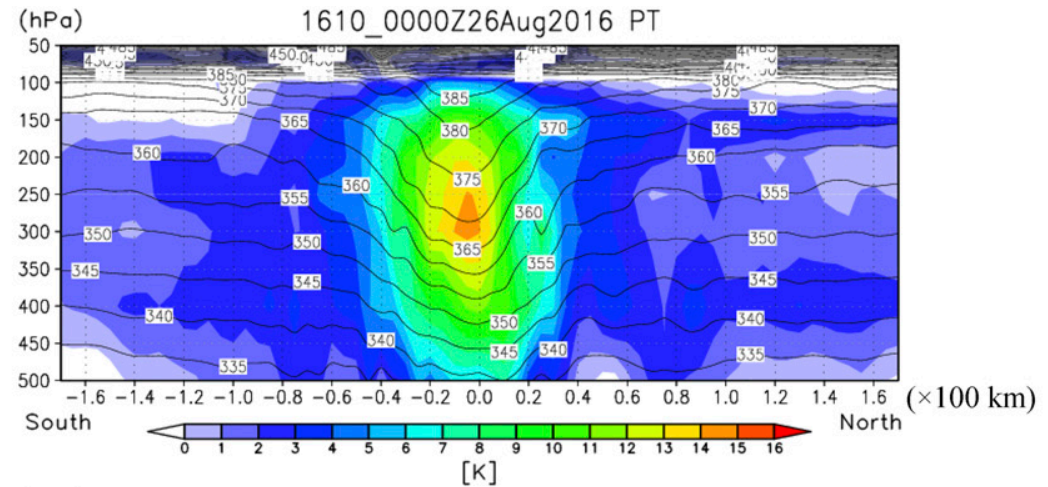

(hPa) 1610_0600Z26Aug2016 PT

(b)

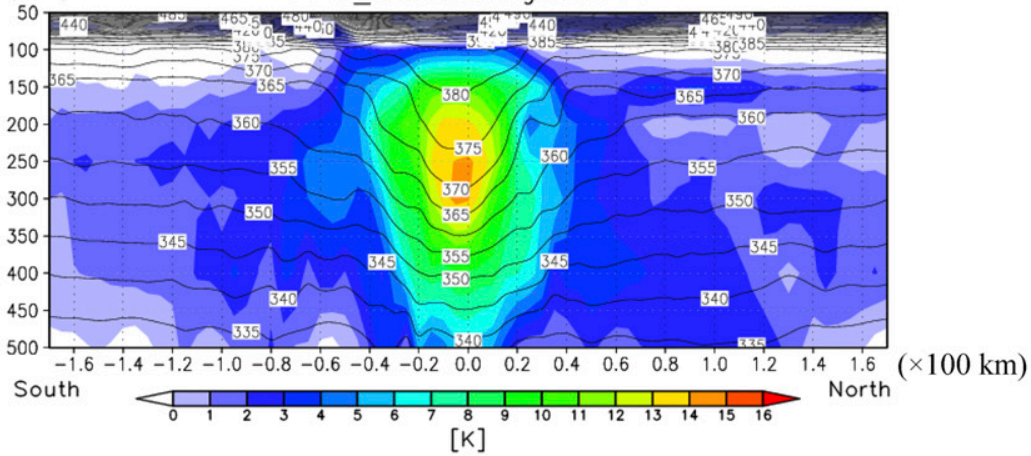

(hPa) 1610_1200Z26Aug2016 PT

(c)

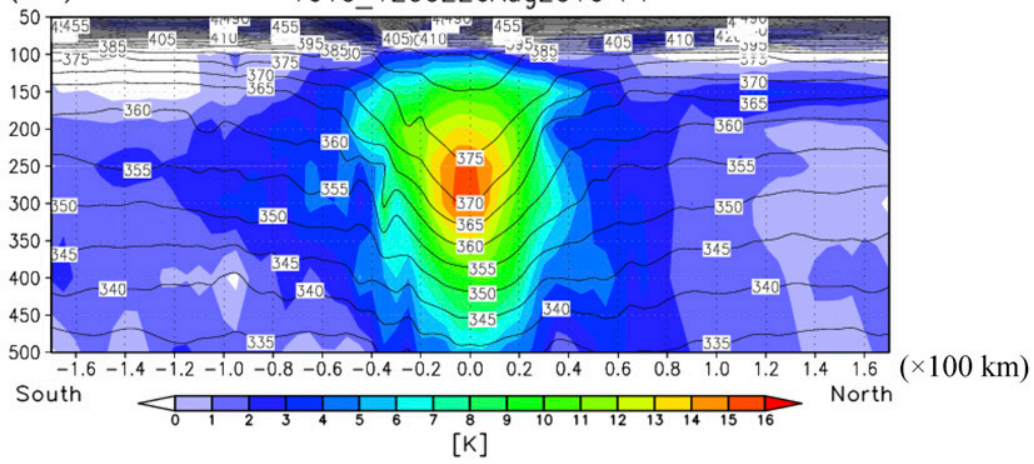

(d)

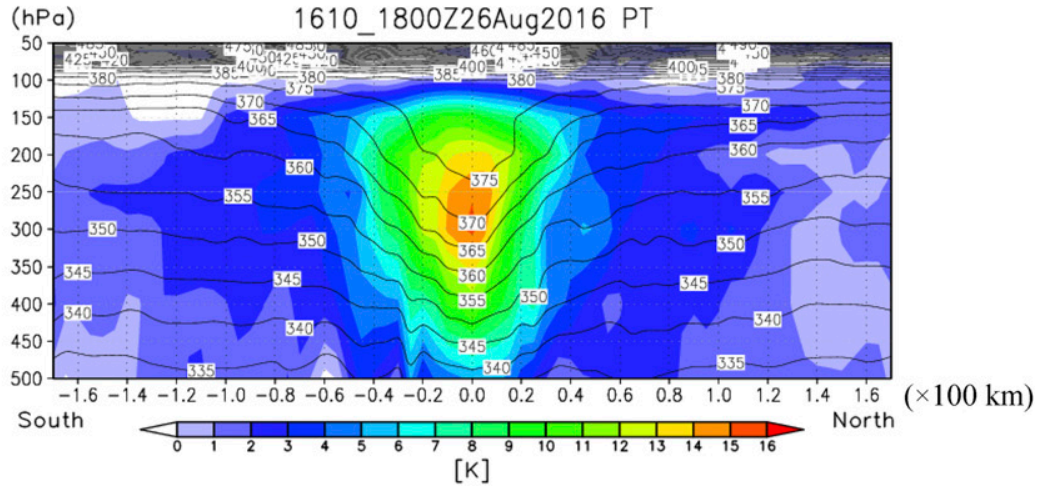

FIG. 14. As in Fig. 13, but for (a) 0000, (b) 0600, (c) 1200, and (d) 1800 UTC 26 Aug 2016 (Period 2). 
(a)
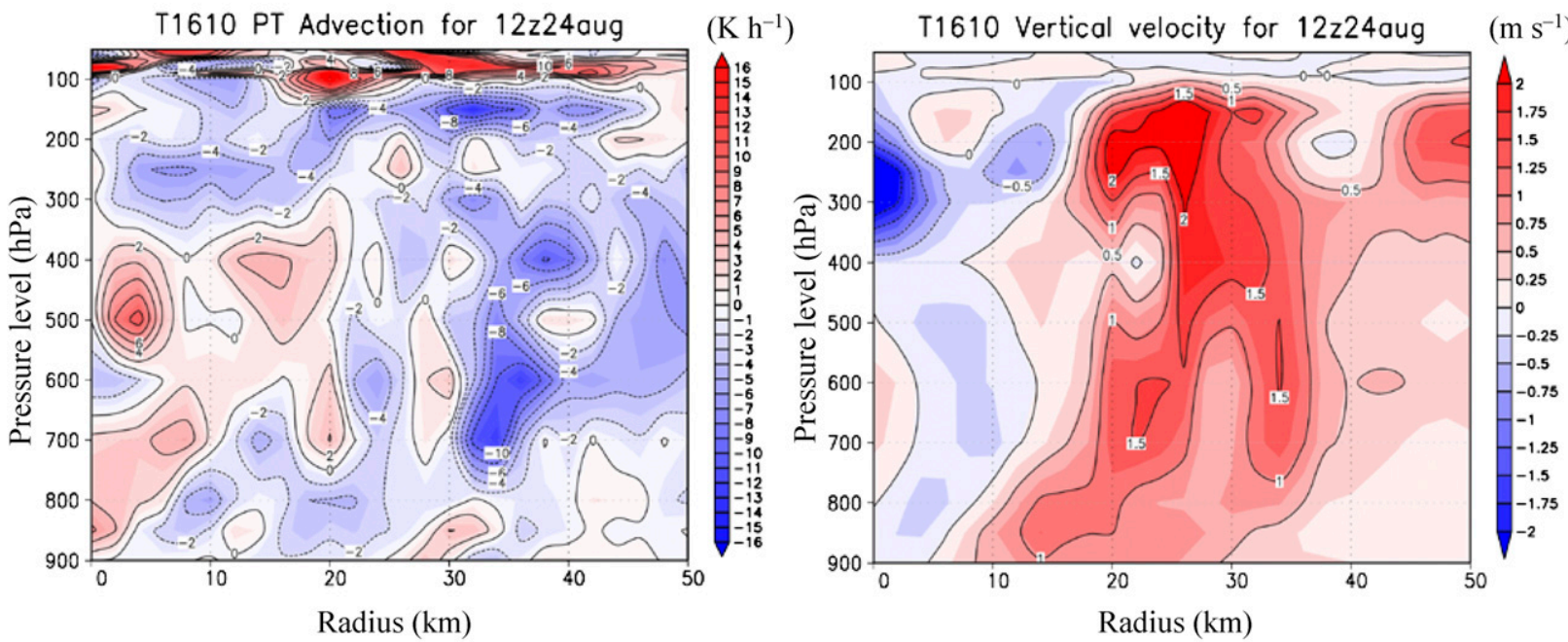

(b)
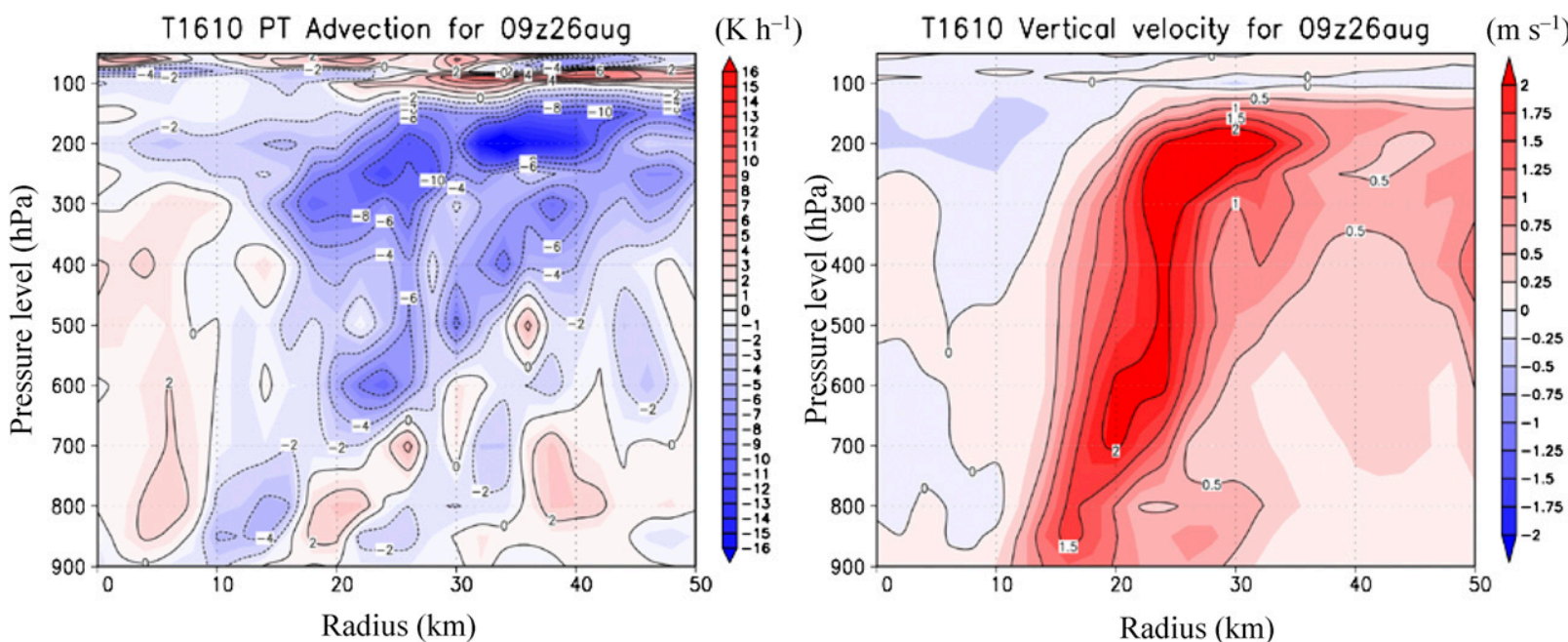

FIG. 15. (left) Potential temperature (PT) advection, and (right) vertical velocity near the center of Typhoon Lionrock (2016) (radius $<$ $50 \mathrm{~km}$ ) in the simulation at the times when the eye downdraft was enhanced. (a) 1200 UTC 24 Aug 2016 (Period 1) and (b) 0900 UTC 26 Aug 2016 (Period 2).

\section{f. Relationship between convective bursts and subsidence within TC eye}

Under the hypothesis that the angular momentum and mass fluxes into the tropopause and lower stratosphere caused by deep convection facilitates subsidence within the eye (Heymsfield et al. 2001; Zhang and Chen 2012; Elsberry et al. 2013; Ohno and Satoh 2015), we investigated the relationship between the strong updrafts associated with vigorous convection in the inner core (i.e., CBs), and subsidence within the eye of Typhoon Lionrock using the time series of the eye downdrafts and the mean updraft for $\mathrm{CB}$ grids in the inner core (Fig. 12c). Eight distinct peaks in the magnitude of the eye downdrafts at 150-250 hPa (arrows in Fig. 12c) appeared during the simulation period; notably, all of the eight peak eye downdrafts tended to occur at approximately the same time or just after the mean updraft at $500 \mathrm{hPa}$ level for CB grids increased and reached 8$9 \mathrm{~m} \mathrm{~s}^{-1}$. The lag correlations between the eye downdraft and the updrafts for $\mathrm{CB}$ grids suggested that the eye downdraft tended to increase $3-9 \mathrm{~h}$ after the updraft associated with CBs increased though the magnitude of the correlation coefficient was not large $(0.42-0.51$ for the lag times from 3 to $9 \mathrm{~h}$; The $P$ value is $6.8 \times 10^{-5}-1.6 \times$ $10^{-4}$ ). This result implies that subsidence within the eye and warm-core intensification were facilitated by CBs. 
TABLE 1. Summary of the warm-core intensification and related phenomena and structural changes during the intensification, mature, and decay phases of the simulated Typhoon Lionrock (2016). 3RMW denotes the radius of RMW multiplied by 3 (section $3 \mathrm{~b}$ ).

\begin{tabular}{|c|c|c|c|}
\hline & $\begin{array}{l}\text { Intensification phase } \\
\text { (including Period 1) }\end{array}$ & $\begin{array}{c}\text { Mature phase } \\
\text { (including Period 2) }\end{array}$ & $\begin{array}{c}\text { Decay phase } \\
\text { (including Period 3) }\end{array}$ \\
\hline $\begin{array}{l}\text { Warm-core maximum } \\
\text { temperature anomaly }\end{array}$ & $\begin{array}{l}\text { Three to four peaks of } \\
\text { temperature anomaly occurred } \\
\text { approximately at } 300 \mathrm{hPa} \text { and } \\
\text { the height gradually ascended. }\end{array}$ & $\begin{array}{l}\text { Four to five peaks of } \\
\text { temperature anomaly } \\
\text { occurred approximately at } \\
300 \mathrm{hPa} \text {. }\end{array}$ & $\begin{array}{l}\text { One peak of temperature } \\
\text { anomaly occurred } \\
\text { approximately at } 300 \mathrm{hPa} \text { and } \\
\text { the height gradually descends. }\end{array}$ \\
\hline $\begin{array}{l}\text { Mean updrafts for CB grids } \\
\text { within a radius of } 3 \mathrm{RMW}\end{array}$ & $\begin{array}{l}\text { Mean updrafts for } \mathrm{CB} \text { grids in the } \\
\text { mid-upper troposphere were } \\
\text { stronger (vertical velocities } \\
\text { greater than } 12 \mathrm{~m} \mathrm{~s}^{-1} \text { ) than } \\
\text { those for Periods } 2 \text { and } 3 \text {. The } \\
\text { peak temperature anomalies } \\
\text { tended to follow the local } \\
\text { maximum of updrafts for CB } \\
\text { grids. }\end{array}$ & $\begin{array}{l}\text { The peak temperature } \\
\text { anomalies tended to follow } \\
\text { the local maximum of the } \\
\text { updrafts for CB grids in the } \\
\text { mid-upper troposphere simi- } \\
\text { lar to those for Period } 1 .\end{array}$ & $\begin{array}{l}\text { The updrafts transiently } \\
\text { increased on } 29 \text { Aug } 2016 \\
\text { when Typhoon Lionrock } \\
\text { made landfall on the } \\
\text { northeastern part of Japan. }\end{array}$ \\
\hline TC inner-core structure & $\begin{array}{l}\text { The eyewall (area of total } \\
\text { precipitable water TPW }> \\
3 \mathrm{~g} \mathrm{~cm}^{-2} \text { ) formed. The } \\
\text { asymmetrization of inner-core } \\
\text { updrafts related to VWS was } \\
\text { found. The number of CB grids } \\
\text { gradually increased with 2-3-h } \\
\text { period variation. }\end{array}$ & $\begin{array}{l}\text { The eyewall was sustained with } \\
\text { variations occurring in TPW } \\
\text { and the axisymmetry. The } \\
\text { number of CB grids gradually } \\
\text { decreased with } 2-3 \text {-h period } \\
\text { variation. }\end{array}$ & $\begin{array}{l}\text { The eyewall decayed and } \\
\text { the number of CB grids } \\
\text { significantly decreased from } \\
\text { those during Periods } 1 \text { and } 2 \text {. }\end{array}$ \\
\hline $\begin{array}{l}\text { Tendency of potential } \\
\text { temperature (PPT) within TC } \\
\text { inner core }\end{array}$ & $\begin{array}{l}\text { The contribution of diabatic } \\
\text { heating to PPT within a radius } \\
\text { of } 10-40 \mathrm{~km} \text { (i.e., the eyewall } \\
\text { region) was significantly large. } \\
\text { Meanwhile, the contribution of } \\
\text { potential temperature (PT) } \\
\text { advection to PPT tended to be } \\
\text { small and negative. }\end{array}$ & $\begin{array}{l}\text { PPT within the eyewall for } \\
\text { Period } 2 \text { was larger than that } \\
\text { for Period } 1 \text {. The contribution } \\
\text { of PT advection was positive } \\
\text { with a downdraft of } 0-0.5 \mathrm{~m} \mathrm{~s}^{-1} \\
\text { in TC eye from the surface to } \\
\text { the tropopause. }\end{array}$ & $\begin{array}{l}\text { Maximum of PPT within the } \\
\text { eyewall decreased due to the } \\
\text { decrease of diabatic heat, } \\
\text { which can be explained by the } \\
\text { weak updrafts within the } \\
\text { eyewall. }\end{array}$ \\
\hline $\begin{array}{l}\text { Periods of enhanced eye } \\
\text { downdrafts }\end{array}$ & $\begin{array}{l}\text { Three periods of enhanced eye } \\
\text { downdrafts existed. }\end{array}$ & $\begin{array}{l}\text { Three periods of enhanced eye } \\
\text { downdrafts existed during } \\
\text { Period } 2 . \text { The magnitudes } \\
\text { were smaller than those for } \\
\text { Period } 1 .\end{array}$ & $\begin{array}{l}\text { Two periods of enhanced eye } \\
\text { downdrafts existed during the } \\
\text { decay phase. The magnitudes } \\
\text { were smaller than those for } \\
\text { Periods } 1 \text { and } 2 \text {. }\end{array}$ \\
\hline
\end{tabular}

\section{Conclusions and discussion}

We investigated $\mathrm{CBs}$ and related warm-core intensification in Typhoon Lionrock (2016) using a $3 \mathrm{~km}$ mesh nonhydrostatic atmosphere model coupled with ocean and ocean wave models developed by MRI/JMA. The simulated track and intensity of Typhoon Lionrock were quite similar to those in the best track data. The simulation showed that the development of Typhoon Lionrock comprised about eight consecutive periods of vigorous convection corresponding to strong updrafts that occurred over intervals of 1 day or less.

Table 1 summarizes the results of the warm-core intensification processes and associated phenomena in the simulation. The warm-core temperature anomaly in the upper troposphere increased as Typhoon Lionrock developed, and the peak height of the warm-core temperature anomaly gradually ascended during the intensification phase. Notably, warm-core intensification tended to follow peak inner-core updrafts caused by the deepening of convection with a lag time of $0-12 \mathrm{~h}$, implying that the warm-core intensity was enhanced by the intensification of the secondary circulation associated with a release of diabatic heat. These results are consistent with the findings of previous numerical studies (Wang and Wang 2014; Ohno and Satoh 2015; Munsell et al. 2018). Aside from this consistency with the previous studies, this study also showed that the extreme updraft by CBs enhancing the warm-core intensity tended to appear on the downshear side, which was induced by the vertical wind shear.

Peaks of tangential winds tended to occur when the warm-core intensity reached a local maximum in the upper troposphere. This overlap indicated that the wind field near the TC center is nearly balanced with the thermal field. Aside from this process, the weak radial inflows in the mid- to lower troposphere seen during the late intensification phase implies that the horizontal 
convergence due to the radial inflow could cause the increase of cyclonic circulation too. In the rapid intensification phase during 23-24 August 2016, the warm core developed rapidly in the upper troposphere during eyewall formation, suggesting that the inner core of Typhoon Lionrock developed as a result of the strong updrafts associated with the deep convection. During the mature phase, the updrafts were relatively small compared to those during the intensification phase and the maximum low-level tangential wind speed gradually decreased.

The budget analysis of PT within the TC inner core illustrated the detailed processes of TC warm-core intensifications. During the intensification phase (Period 1), the diabatic heating explained most of the PT tendency within the radii of $10-40 \mathrm{~km}$ while the contribution of PT advection to the PT tendency tended to be small. During the intensification phase to the mature phase (Period 2), the updrafts within the eyewall became stronger than those during Period 1, and were limited within the radii of $10-35 \mathrm{~km}$, causing the increase in diabatic heat. The PT advection within the eye was positive from the surface to the tropopause with a downdraft of $0-0.5 \mathrm{~m} \mathrm{~s}^{-1}$ within the eye, suggesting the subsidence of high-PT air. During the decay phase (Period 3), the PT tendency became significantly smaller than those for the intensification and mature phases because the diabatic heat generated within the eyewall was small.

We identified the influence of adiabatic heating within the eye on warm-core intensification by analyzing the time series of the maximum temperature anomaly, eye downdrafts, and updraft within the TC inner core for CB grids. Increased subsidence within the eye tended to precede increases of the maximum temperature anomaly within the eye by $0-12 \mathrm{~h}$; the descending air originated near the tropopause. Also CBs, parts of which are related to deep convection associated with the diurnal cycle, could facilitate the subsidence within the eye and warm-core intensification. The updrafts associated with CBs tended to precede the subsidence by $3-9 \mathrm{~h}$.

Based on the results considering the simulated Typhoon Lionrock, we conclude that diabatic heating due to the inner-core convection can explain the atmospheric warming within the TC inner core and that the contribution of adiabatic heating to the increase in the PT in the eye was relatively larger than that of the diabatic heating. Further, this study indicated that CBs could play an essential role in the enhancement of eye downdraft which could intensify the warm core. To obtain a more general relationship between CBs and warm-core intensification, case studies of other TCs are necessary because the warm-core structure varies depending on cyclone intensity and structure (Durden 2013). Future numerical studies using a high-resolution nonhydrostatic model to investigate the detailed processes (e.g., radiative processes) that influence the diurnal cycle and other variations in TC convection would prove useful to our better understanding of the relationship between CBs and warm-core intensification (Navarro and Hakim 2016). Continued studies based on observational data (Halverson et al. 2006; Stern and Zhang 2016; Komaromi and Doyle 2017) will complement results from the numerical studies.

Acknowledgments. The authors thank Dr. Wataru Yanase and Dr. Sachie Kanada for useful discussion on this study. We also thank to the three anonymous reviewers for their beneficial comments and suggestions on an earlier version of the manuscript. A part of this work was supported by JSPS KAKENHI Grants JP15K05292 and JP18K03747.

\section{REFERENCES}

Bao, J. W., J. M. Wilczak, J. K. Choi, and L. H. Kantha, 2000: Numerical simulations of air-sea interaction under high wind conditions using a coupled model: A study of hurricane development. Mon. Wea. Rev., 128, 2190-2210, https://doi.org/ 10.1175/1520-0493(2000)128<2190:NSOASI >2.0.CO;2.

Braun, S. A., and W.-K. Tao, 2000: Sensitivity of high-resolution simulations of Hurricane Bob (1991) to planetary boundary layer parameterizations. Mon. Wea. Rev., 128, 3941-3961, https://doi.org/10.1175/1520-0493(2000)129<3941:SOHRSO> 2.0.CO;2.

Bryan, G. H., and R. Rotunno, 2009: Evaluation of an analytical model for the maximum intensity of tropical cyclones. J. Atmos. Sci., 66, 3042-3060, https://doi.org/10.1175/2009JAS3038.1.

Chen, H., and D. Zhang, 2013: On the rapid intensification of Hurricane Wilma (2005). Part II: Convective bursts and the upper-level warm core. J. Atmos. Sci., 70, 146-162, https:// doi.org/10.1175/JAS-D-12-062.1.

Cram, T. A., J. Persing, M. T. Montgomery, and S. A. Braun, 2007: A Lagrangian trajectory view on transport and mixing processes between the eye, eyewall, and environment using a highresolution simulation of Hurricane Bonnie (1998). J. Atmos. Sci., 64, 1835-1856, https://doi.org/10.1175/JAS3921.1.

Croxford, M., and G. M. Barnes, 2002: Inner core strength of Atlantic tropical cyclones. Mon. Wea. Rev., 130, 127-139, https://doi.org/ 10.1175/1520-0493(2002)130<0127:ICSOAT>2.0.CO;2.

Deardorff, J. W., 1980: Stratocumulus-capped mixed layers derived from a three-dimensional model. Bound.-Layer Meteor., 18, 495-527, https://doi.org/10.1007/BF00119502.

Dunion, J. P., C. D. Thorncroft, and C. S. Velden, 2014: The tropical cyclone diurnal cycle of mature hurricanes. Mon. Wea. Rev., 142, 3900-3919, https://doi.org/10.1175/MWR-D-13-00191.1.

Durden, S. L., 2013: Observed tropical cyclone eye thermal anomaly profiles extending above $300 \mathrm{hPa}$. Mon. Wea. Rev., 141, 4256-4268, https://doi.org/10.1175/MWR-D-13-00021.1.

Elsberry, R. L., L. Chen, J. Davidson, R. Rogers, Y. Wang, and $\mathrm{L}$. Wu, 2013: Advances in understanding and forecasting rapidly changing phenomena in tropical cyclones. Trop. Cyclone Res. Rev., 2, 13-24.

Fierro, A. O., and J. M. Reisner, 2011: High-resolution simulation of the electrification and lightning of Hurricane Rita during 
the period of rapid intensification. J. Atmos. Sci., 68, 477-494, https://doi.org/10.1175/2010JAS3659.1.

Gallina, G. M., and C. S. Velden, 2002: Environmental vertical wind shear and tropical cyclone intensity change utilizing enhanced satellite derived wind information. 25th Conf. on Hurricanes and Tropical Meteorology, San Diego, CA, Amer. Meteor. Soc., 3C.5, https://ams.confex.com/ams/25HURR/ techprogram/paper_35650.htm.

Gelsthorpe, R. V., E. Schied, and J. J. W. Wilson, 2000: ASCATMetop's advanced scatterometer. ESA Bull., 102, 19-27, https:// pdfs.semanticscholar.org/bb73/3c1f037c0f6049c41ab97fca8d7b376074de.pdf.

Guimond, S. R., G. M. Heymsfield, and F. J. Turk, 2010: Multiscale observations of Hurricane Dennis (2005): The effects of hot towers on rapid intensification. J. Atmos. Sci., 67, 633-654, https://doi.org/10.1175/2009JAS3119.1.

,,-- P. D. Reasor, and A. C. Didlake Jr., 2016: The rapid intensification of Hurricane Karl (2010): New remote sensing observations of convective bursts from the Global Hawk platform. J. Atmos. Sci., 73, 3617-3639, https://doi.org/10.1175/ JAS-D-16-0026.1.

Halverson, J. B., J. Shimson, G. Heymsfield, H. Pierce, T. Hock, and L. Ritchie, 2006: Warm core structure of Hurricane Erin diagnosed from high altitude dropsondes during CAMEX-4. J. Atmos. Sci., 63, 309-324, https://doi.org/10.1175/JAS3596.1.

Hazelton, A. T., R. F. Rogers, and R. E. Hart, 2017: Analyzing simulated convective bursts in two Atlantic hurricanes. Part I: Burst formation and development. Mon. Wea. Rev., 145, 30733094, https://doi.org/10.1175/MWR-D-16-0267.1.

Heymsfield, G. M., J. B. Halverson, J. Simpson, L. Tian, and T. P. Bui, 2001: ER-2 Doppler radar investigations of the eyewall of Hurricane Bonnie during the Convection and Moisture Experiment-3. J. Appl. Meteor., 40, 1310-1330, https://doi.org/ 10.1175/1520-0450(2001)040<1310:EDRIOT>2.0.CO;2.

Houze, R. A., Jr., 2010: Clouds in tropical cyclones. Mon. Wea. Rev., 138, 293-344, https://doi.org/10.1175/2009MWR2989.1.

Ikawa, M., and K. Saito, 1991: Description of a nonhydrostatic model developed at the forecast research department of the MRI. Meteorological Research Institute Tech. Rep. 28, $238 \mathrm{pp}$.

Kaplan, J., and M. DeMaria, 2003: Large-scale characteristics of rapidly intensifying tropical cyclones in the North Atlantic basin. Wea. Forecasting, 18, 1093-1108, https://doi.org/10.1175/ 1520-0434(2003)018<1093:LCORIT>2.0.CO;2.

Kieu, C., V. Tallapragada, D.-L. Zhang, and Z. Moon, 2016: On the development of double warm-core structures in intense tropical cyclones. J. Atmos. Sci., 73, 4487-4506, https://doi.org/ 10.1175/JAS-D-16-0015.1.

Kishimoto, K., M. Sasaki, and M. Kunitsugu, 2013: Cloud grid information objective Dvorak analysis (CLOUD) at the RSMC Tokyo-Typhoon Center. RSMC Tokyo-Typhoon Center Technical Review, Tech. Rep. 15, 15 pp.

Klemp, J. B., and R. Wilhelmson, 1978: The simulation of threedimensional convective storm dynamics. J. Atmos. Sci., 35, 1070-1096, https://doi.org/10.1175/1520-0469(1978)035<1070: TSOTDC $>2.0 . \mathrm{CO} ; 2$.

Komaromi, W. A., and J. D. Doyle, 2017: Tropical cyclone outflow and warm core structure as revealed by HS3 dropsonde data. Mon. Wea. Rev., 145, 1339-1359, https://doi.org/10.1175/ MWR-D-16-0172.1.

Kossin, J. P., 2002: Daily hurricane variability inferred from GOES infrared imagery. Mon. Wea. Rev., 130, 2260-2270, https://doi.org/ 10.1175/1520-0493(2002)130<2260:DHVIFG >2.0.CO;2.
— and M. D. Eastin, 2001: Two distinct regimes in the kinematic and thermodynamic structure of the hurricane eye and eyewall. J. Atmos. Sci., 58, 1079-1090, https://doi.org/10.1175/ 1520-0469(2001)058<1079:TDRITK > 2.0.CO;2.

Lajoie, F., and I. Butterworth, 1984: Oscillation of high-level cirrus and heavy precipitation around Australian region tropical cyclones. Mon. Wea. Rev., 112, 535-544, https://doi.org/ 10.1175/1520-0493(1984)112<0535:OOHLCA $>2.0$.CO;2.

Lander, M., 1994: Description of a monsoon gyre and its effects on the tropical cyclones in the western North Pacific during August 1991. Wea. Forecasting, 9, 640-654, https://doi.org/ 10.1175/1520-0434(1994)009<0640:DOAMGA > 2.0.CO;2.

Li, Q.-Q., and Y. Wang, 2012: A comparison of inner and outer spiral rainbands in a numerically simulated tropical cyclone. Mon. Wea. Rev., 140, 2782-2805, https://doi.org/10.1175/ MWR-D-11-00237.1.

Lin, Y. H., R. D. Farley, and H. D. Orville, 1983: Bulk parameterization of the snow field in a cloud model. J. Climate Appl. Meteor., 22, 1065-1092, https://doi.org/10.1175/1520-0450(1983) 022<1065:BPOTSF $>2.0 . \mathrm{CO} ; 2$.

Melhauser, C., and F. Zhang, 2014: Diurnal radiation cycle impact on the pregenesis environment of Hurricane Karl (2010). J. Atmos. Sci., 71, 1241-1259, https://doi.org/10.1175/JAS-D-13-0116.1.

Munsell, E. B., F. Zhang, S. A. Braun, J. A. Sippel, and A. C. Didlake, 2018: The inner-core temperature structure of Hurricane Edouard (2014): Observations and ensemble variability. Mon. Wea. Rev., 146, 135-155, https://doi.org/10.1175/ MWR-D-17-0095.1.

Muramatsu, T., 1983: Diurnal variations of satellite-measured TBB areal distribution and eye diameter of mature typhoons. J. Meteor. Soc. Japan, 61, 77-90, https://doi.org/10.2151/jmsj1965.61.1_77.

Navarro, E. L., and G. J. Hakim, 2016: Idealized numerical modeling of the diurnal cycle of tropical cyclones. J. Atmos. Sci., 73, 4189-4201, https://doi.org/10.1175/JAS-D-15-0349.1.

,-- , and H. E. Willoughby, 2017: Balanced response of an axisymmetric tropical cyclone to periodic diurnal heating. J. Atmos. Sci., 74, 3325-3337, https://doi.org/10.1175/JAS-D-16-0279.1.

Nguyen, M. C., M. J. Reeder, N. E. Davidson, R. K. Smith, and M. T. Montgomery, 2011: Inner-core vacillation cycles during the intensification of Hurricane Katrina. Quart. J. Roy. Meteor. Soc., 137, 829-844, https://doi.org/10.1002/qj.823.

Ohno, T., and M. Satoh, 2015: On the warm core of a tropical cyclone formed near the tropopause. J. Atmos. Sci., 72, 551-571, https://doi.org/10.1175/JAS-D-14-0078.1.

Oyama, R., 2014: Estimation of tropical cyclone central pressure from warm core intensity observed by the Advanced Microwave Sounding Unit-A (AMSU-A). Pap. Meteor. Geophys., 65, 35-56, https://doi.org/10.2467/mripapers.65.35.

_ 2017: Relationship between tropical cyclone intensification and cloud-top outflow revealed by upper-tropospheric atmospheric motion vectors. J. Appl. Meteor. Climatol., 56, 28012819, https://doi.org/10.1175/JAMC-D-17-0058.1.

_- M. Sawada, and K. Shimoji, 2018: Diagnosis of tropical cyclone intensity and structure using upper tropospheric Atmospheric Motion Vectors. J. Meteor. Soc. Japan, 96B, 3 26, https://doi.org/10.2151/jmsj.2017-024.

Paterson, L. A., B. N. Hanstrum, N. E. Davidson, and H. C. Weber, 2005: Influence of environmental vertical wind shear on the intensity of hurricane-strength tropical cyclones in the Australian region. Mon. Wea. Rev., 133, 3644-3660, https://doi.org/ 10.1175/MWR3041.1.

Paull, G., K. Menelaou, and M. K. Yau, 2017: Sensitivity of tropical cyclone intensification to axisymmetric heat sources: The role of 
inertial stability. J. Atmos. Sci., 74, 2325-2340, https://doi.org/ 10.1175/JAS-D-16-0298.1.

Rogers, R., 2010: Convective-scale structure and evolution during a high-resolution simulation of tropical cyclone rapid intensification. J. Atmos. Sci., 67, 44-70, https://doi.org/10.1175/2009JAS3122.1.

— - P. Reasor, and S. Lorsolo, 2013: Airborne Doppler observations of the inner-core structural differences between intensifying and steady-state tropical cyclones. Mon. Wea. Rev., 141, 2970-2991, https://doi.org/10.1175/MWR-D-12-00357.1.

— P. D. Reasor, and J. A. Zhang, 2015: Multiscale structure and evolution of Hurricane Earl (2010) during rapid intensification. Mon. Wea. Rev., 143, 536-562, https://doi.org/ 10.1175/MWR-D-14-00175.1.

Saito, K., 2012: The JMA nonhydrostatic model and its applications to operation and research. Atmospheric Model Applications, I. Yucel, Ed., InTech, 85-110, https://doi.org/10.5772/35368.

Satoh, M., and Coauthors, 2014: The non-hydrostatic icosahedral atmospheric model: Description and development. Prog. Earth Planet. Sci., 1, 18, https://doi.org/10.1186/s40645-014-0018-1.

Sawada, M., and T. Iwasaki, 2007: Impacts of ice phase processes on tropical cyclone development. J. Meteor. Soc. Japan, $\mathbf{8 5}$, 479-494, https://doi.org/10.2151/jmsj.85.479.

Schubert, W., M. T. Montgomery, R. K. Taft, T. A. Guinn, S. R. Fulton, J. P. Kossin, and J. P. Edwards, 1999: Polygonal eyewalls, asymmetric eye contraction, and potential vorticity mixing in hurricanes. J. Atmos. Sci., 56, 1197-1223, https://doi.org/ 10.1175/1520-0469(1999)056<1197:PEAECA > 2.0.CO;2.

Shapiro, L. J., and H. E. Willoughby, 1982: The response of balanced hurricanes to local sources of heat and momentum. J. Atmos. Sci., 39, 378-394, https://doi.org/10.1175/ 1520-0469(1982)039<0378:TROBHT>2.0.CO;2.

Smith, R. K., and G. L. Thomsen, 2010: Dependence of tropicalcyclone intensification on the boundary-layer representation in a numerical model. Quart. J. Roy. Meteor. Soc., 136, 16711685, https://doi.org/10.1002/qj.687.

Steranka, J., E. B. Rodgers, and R. C. Gentry, 1986: The relationship between satellite measured convective bursts and tropical cyclone intensification. Mon. Wea. Rev., 114, 1539-1546, https:// doi.org/10.1175/1520-0493(1986)114<1539:TRBSMC > 2.0.CO;2.

Stern, D. P., and F. Zhang, 2016: The warm-core structure of Hurricane Earl (2010). J. Atmos. Sci., 73, 3305-3328, https:// doi.org/10.1175/JAS-D-15-0328.1.

Sugi, M., K. Kuma, K. Tada, K. Tamiya, H. Hasegawa, T. Iwasaki, S. Yamada, and T. Kitade, 1990: Description and performance of the JMA operational global spectral model (JMA-GSM88). Geophys. Mag., 43, 105-130.

Takeda, T., and R. Oyama, 2003: Periodic time variation of lowTBB cloud area in typhoon. J. Meteor. Soc. Japan, 81, 14971503, https://doi.org/10.2151/jmsj.81.1497.

Tang, X., and F. Zhang, 2016: Impacts of the diurnal radiation cycle on the formation, intensity, and structure of Hurricane Edouard (2014). J. Atmos. Sci., 73, 2871-2892, https://doi.org/ 10.1175/JAS-D-15-0283.1.
Taylor, P. K., and M. J. Yelland, 2001: The dependence of sea surface roughness on the height and steepness of the waves. J. Phys. Oceanogr., 31, 572-590, https://doi.org/10.1175/ 1520-0485(2001)031<0572:TDOSSR > 2.0.CO;2.

Ueno, M., 2007: Observational analysis and numerical evaluation of the effects of vertical wind shear on the rainfall asymmetry in the typhoon inner-core region. J. Meteor. Soc. Japan, 85, 115-136, https://doi.org/10.2151/jmsj.85.115.

Usui, N., S. Ishizaki, Y. Fujii, H. Tsujino, T. Yasuda, and M. Kamachi, 2006: Meteorological Research Institute multivariate ocean variational estimation (MOVE) system: Some early results. Adv. Space Res., 37, 806-822, https://doi.org/ 10.1016/j.asr.2005.09.022.

Vigh, J. L., and W. H. Schubert, 2009: Rapid development of the tropical cyclone warm core. J. Atmos. Sci., 66, 3335-3350, https://doi.org/10.1175/2009JAS3092.1.

Wada, A., 2015: Unusually rapid intensification of Typhoon Man-yi in 2013 under preexisting warm-water conditions near the Kuroshio front south of Japan. J. Oceanogr., 71, 597-622, https://doi.org/10.1007/s10872-015-0273-9.

- and R. Oyama, 2018: Relation of convective bursts to changes in the intensity of Typhoon Lionrock (2016) during the decay phase simulated by an atmosphere-wave-ocean coupled model. J. Meteor. Soc. Japan, 96, 489-509, https://doi.org/ 10.2151/jmsj.2018-052.

- N. Kohno, and Y. Kawai, 2010: Impact of wave-ocean interaction on Typhoon Hai-Tang in 2005. SOLA, 6A, 13-16.

Wang, H., and Y. Wang, 2014: A numerical study of Typhoon Megi (2010). Part I: Rapid intensification. Mon. Wea. Rev., 142, 2948, https://doi.org/10.1175/MWR-D-13-00070.1.

Wang, Y., 2009: How do outer spiral rainbands affect tropical cyclone structure and intensity? J. Atmos. Sci., 66, 1250-1273, https://doi.org/10.1175/2008JAS2737.1.

Willoughby, H. E., 1998: Tropical cyclone eye thermodynamics. Mon. Wea. Rev., 126, 3053-3067, https://doi.org/10.1175/ 1520-0493(1998)126<3053:TCET>2.0.CO;2.

Wong, M. L., and J. C. L. Chan, 2004: Tropical cyclone intensity in vertical wind shear. J. Atmos. Sci., 61, 1859-1876, https:// doi.org/10.1175/1520-0469(2004)061<1859:TCIIVW>2.0.CO;2.

Wu, L., H. Zong, and J. Liang, 2013: Observational analysis of tropical cyclone formation associated with monsoon gyres. J. Atmos. Sci., 70, 1023-1034, https://doi.org/10.1175/JAS-D-12-0117.1.

Zehr, R. M., 1992: Tropical cyclogenesis in the western North Pacific. NOAA Tech. Rep. NESDIS 61, 181 pp.

_ J. A. Knaff, and M. DeMaria, 2008: Tropical cyclone environmental vertical wind shear analysis using a microwave sounder. 28th Conf. on Hurricanes and Tropical Meteorology, Orlando, FL, Amer. Meteor. Soc., 14B.2, https://ams.confex.com/ams/ 28Hurricanes/techprogram/paper_137917.htm.

Zhang, D., and H. Chen, 2012: Importance of the upper-level warm core in the rapid intensification of a tropical cyclone. Geophys. Res. Lett., 39, L02806, https://doi.org/10.1029/ 2011 GL050578. 